\title{
Review Article \\ Pleiotropic Effects of Thyroid Hormones: Learning from Hypothyroidism
}

\author{
Martha Franco, ${ }^{1}$ Edmundo Chávez, ${ }^{2}$ and Oscar Pérez-Méndez ${ }^{3}$ \\ ${ }^{1}$ Department of Nephrology, Instituto Nacional de Cardiología Ignacio Chávez, Juan Badiano 1, \\ 14080 Mexico City, DF, Mexico \\ ${ }^{2}$ Department of Biochemistry, Instituto Nacional de Cardiología Ignacio Chávez, Juan Badiano 1, 14080 Mexico City, DF, Mexico \\ ${ }^{3}$ Department of Molecular Biology, Instituto Nacional de Cardiología Ignacio Chávez, Juan Badiano 1, 14080 Mexico City, DF, Mexico
}

Correspondence should be addressed to Martha Franco, marthafranco@lycos.com

Received 29 January 2011; Revised 29 March 2011; Accepted 30 March 2011

Academic Editor: Juan Bernal

Copyright ( $) 2011$ Martha Franco et al. This is an open access article distributed under the Creative Commons Attribution License, which permits unrestricted use, distribution, and reproduction in any medium, provided the original work is properly cited.

Hypothyroidism induces several metabolic changes that allow understanding some physiopathological mechanisms. Under experimental hypothyroid conditions in rats, heart and kidney are protected against oxidative damage induced by ischemia reperfusion. An increased resistance to opening of the permeability transition pore seems to be at the basis of such protection. Moreover, glomerular filtration rate of hypothyroid kidney is low as a result of adenosine receptors-induced renal vasoconstriction. The vascular tone of aorta is also regulated by adenosine in hypothyroid conditions. In other context, thyroid hormones regulate lipoprotein metabolism. High plasma level of LDL cholesterol is a common feature in hypothyroidism, due to a low expression of the hepatic LDL receptor. In contrast, HDL-cholesterol plasma levels are variable in hypothyroidism; several proteins involved in HDL metabolism and structure are expressed at lower levels in experimental hypothyroidism. Based on the positive influence of thyroid hormones on lipoprotein metabolism, thyromimetic drugs are promising for the treatment of dyslipidemias. In summary, hypothyroid status has been useful to understand molecular mechanisms involved in ischemia reperfusion, regulation of vascular function and intravascular metabolism of lipoproteins.

\section{Introduction}

The influence of thyroid hormones on metabolic processes has been widely recognized, particularly the profound changes in ATP metabolism. ATP production is primarily driven by mitochondrion, along with other relevant processes, including intracellular $\mathrm{Ca}^{2+}$ regulation, redox signaling, and apoptosis triggering [1]. In this respect, it is known that hypothyroidism diminishes oxygen consumption and promotes low metabolism that lead to disturbances in hemodynamic, cardiac, and renal functions, as well as in lipid metabolism.

Adenosine is a vasoactive compound that may induce dysfunction of several physiological mechanisms. In this regard, little attention has been given to the relationship between the effects of the nucleoside adenosine, a metabolite of ATP, and the thyroid status, specifically in hypothyroidism. Lipoproteins profile is another aspect affected in hypothyroidism; increased low-density lipoproteins- (LDL-) cholesterol plasma levels is the most common feature. The metabolism of high-density lipoproteins (HDLs) is also deeply impaired; several genes coding for proteins involved in the intravascular metabolism of HDL are regulated by thyroid hormones. However, the altered HDL metabolism has not been considered in its real dimension because HDL-cholesterol plasma levels vary widely among different studies in patients or animal models of hypothyroidism.

In this paper, we will focus on hypothyroidism as model to understand new physiological mechanisms that influence the mitochondrion, the cardiovascular system, the regulation of vascular tone, the kidney, and lipid metabolism.

\section{Hypothyroidism and Mitochondria}

Thyroid hormones regulate the expression of several membrane-associated respiratory enzymes and metabolite carriers in mitochondria; whether the effect of such regulation is deleterious or beneficial remains controversial [1-5]. 
In hypothyroidism, it is known that the electron transport chain complexes and the $F_{1}-F_{o}$ ATPase decrease their activity in many tissues $[6,7]$. Also cardiolipin, a dimeric phospholipid synthesized by the mitochondrial enzyme cardiolipin synthase, is activated by the thyroid hormones [8]. As a consequence, lower mitochondrial content of this phospholipid has been reported in hypothyroidism, contributing to the constellation of intracellular abnormalities in this physiopathological situation $[9,10]$. The function of several mitochondrial proteins seems to be related to cardiolipin content. Paradies et al. [11] showed that the activity of cytochrome c oxidase was diminished in mitochondria isolated from hypothyroid rats, and that its normal activity was recovered after the addition of cardiolipin. Other mitochondrial protein affected by the hypothyroid status is the adenine nucleotide translocase (ANT). Normal ADP/ATP exchange activity of ANT depends on cardiolipin [12]; Paradies et al. [11] demonstrated that cardiolipin content in liver mitochondria from hypothyroid rats was $24 \mathrm{nmol} / \mathrm{mg}$ versus $40 \mathrm{nmol} / \mathrm{mg}$ in euthyroid rats. These values correlated with a diminution in ANT levels, from $58 \mathrm{nmol} / \mathrm{mg}$ in control rats to $40 \mathrm{nmol} / \mathrm{mg}$ in hypothyroid rats. In addition to its normal function, ANT forms the inner membrane channel of the mitochondrial permeability transition pore (MPTP) [13-15] which allows the movement of matrix ions and metabolites through the mitochondrial membrane (Figure 1). Binding of cyclophilin-D (CyP-D) to ANT matrix surface facilitates a calcium-triggered conformational change converting it from a specific transporter to a nonspecific pore. Both proteins along with the voltage-dependent anion channel (VDAC) and cardiolipin probably represent the minimum MPTP configuration [13-15]. Once integrated, MPTP opening is favored by $\mathrm{Ca}^{2+}$ accumulation in the matrix or by inhibiting the ADP/ATP translocase activity with the specific inhibitor carboxyatractyloside (CAT) [16]. As mentioned above, the translocase activity in the membrane depends on the lipid constitution of the bilayer, in other words, on the cardiolipin content $[17,18]$. Since mitochondria from hypothyroid rats are characterized by low cardiolipin content and by low expression of ANT [11], MPTP formation in these mitochondria is impaired [17]. Experiments carried out with mitochondria from thyroidectomized rats, whose blood $\mathrm{T}_{4}$ levels diminished from $6.42 \pm 0.024$ to $1.49 \pm 0.12 \mu \mathrm{g} / \mathrm{dL}$ after surgery, showed that the transition pore remained closed, regardless of the $\mathrm{Ca}^{2+}$ overload [17].

A controversial issue in hypothyroidism is the apparent protection against tissue injury derived from ischemia reperfusion [18-20]. Tissue injury by reperfusion is an important complication involved in organ transplantation; in kidney transplantation, a delay in graft function has been attributed to the deleterious effect of excessive release of reactive oxygen species (ROS) [21]. The increased production of ROS induces a leakage of mitochondria matrix components, likely as a consequence of membrane protein and lipid peroxidation [22]. Mitochondrial membrane increased permeability leads to massive $\mathrm{Ca}^{2+}$ loss; in mitochondria isolated from euthyroid-rat kidneys subjected to ischemia/reperfusion, the initial $\mathrm{Ca}^{2+}$ accumulation inside mitochondria was followed almost immediately by a slow release of the cation. In
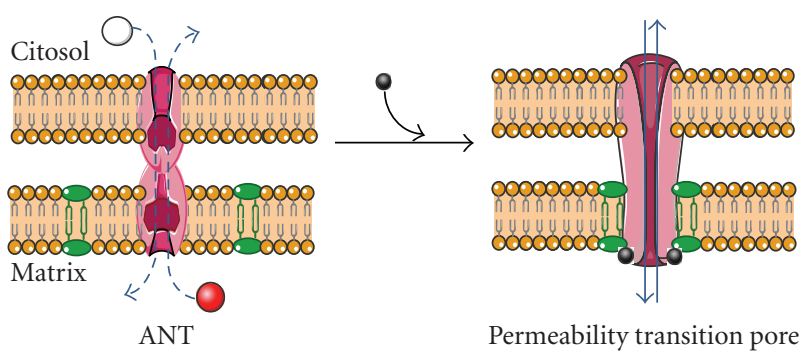

(a)

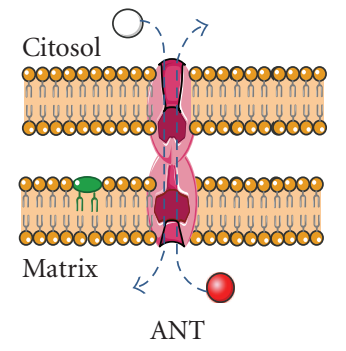

$\begin{array}{ll}\bigcirc & \text { ADP } \\ \bigcirc & \text { ATP } \\ \text { - } & \mathrm{Ca}^{2+}\end{array}$

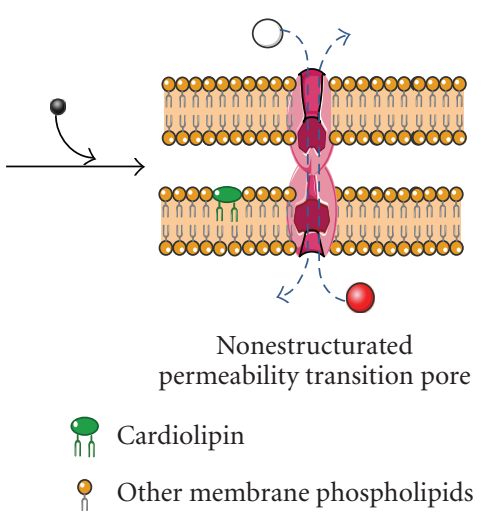

(b)
Figure 1: Conversion of the adenine nucleotide translocase (ANT) to permeability transition pore. (a) Under euthyroid conditions, ANT allows the selective exchange (dotted lines) of ADP and ATP between the citosol and the mitochondrion matrix. $\mathrm{Ca}^{2+}$ triggers the assembling of ANT with cardiolipin and other proteins (not shown in the figure) to integrate the permeability transition pore. (b) In hypothyroidism, the low content of cardiolipin in the mitochondrion membrane limits the pore formation, thus conserving the ANT function and matrix content unaltered. See the text for details.

contrast, mitochondria isolated from ischemic/reperfused kidney of hypothyroid rats were capable of maintaining the accumulated $\mathrm{Ca}^{2+}$.

Oxidative stress induces opening of the pore, which allows depletion of several compounds from the mitochondrial matrix including $\mathrm{NAD}^{+}$and cytochrome $\mathrm{c}[19$, 23]. In this context, $\mathrm{NAD}^{+}$and cytochrome $\mathrm{c}$ content in kidney mitochondria also depend on thyroid status. Matrix $\mathrm{NAD}^{+}$fell down to about $10 \%$ of control levels in mitochondria isolated from euthyroid rats after ischemia/reperfusion. In contrast, matrix $\mathrm{NAD}^{+}$increased around $40 \%$ in mitochondria isolated from hypothyroid rats subjected to ischemia/reperfusion with respect to control mitochondria. As previously reported, the MPTP lies under the progression of the apoptotic mitochondrial pathway, providing mitochondrial cytochrome c release [19, 23]. Mitochondria isolated from ischemic/reperfused euthyroid kidney showed lower levels of cytochrome c, as compared with mitochondria isolated from reperfused kidney from hypothyroid rats (40\% versus 10\%) [19].

Hypothyroidism protection, against nonspecific membrane leakage, has also been shown by using inhibitors of the electron transport and oxidative phosphorylation uncouplers $[19,20]$. 
Based on the aforementioned evidence, we can suggest that the thyroid status influences mitochondrial membrane permeability, that is, hypothyroidism renders mitochondria membrane less prone to leak calcium. In support of the evidence mentioned above, it is important to mention that mitochondria isolated from hyperthyroid rats have an increased nonspecific permeability, since they undergo permeability transition in the absence of inducing agents [24]. The resistance to increased permeability in mitochondria from hypothyroid rats should be due to the inability of ANT to convert itself into a nonspecific pore. Such a failure must be attributed to the low content of cardiolipin, which is part of the annulus of the carrier $[12,15]$ and is indispensable for its adequate function. Furthermore, it has been proposed that cardiolipin would be the target site for $\mathrm{Ca}^{2+}$ to induce pore opening (Figure 1). Therefore, in mitochondria with low content of cardiolipin, $\mathrm{Ca}^{2+}$ fails to induce membrane leakage. It should be noted that cardiolipin content in kidney mitochondria from hypothyroid rats was about $60 \%$ of those isolated from control rats [25].

Thyroid hormones affect other mitochondrial functions that are mediated by mechanisms different to the cardiolipin membrane content; hypothyroidism affects the expression of mitochondrial proteins from the respiratory chain. In this regard, it has been shown that Coenzyme Q10 levels decreased, as well as the antioxidant capacity of mitochondria $[26,27]$. Of particular interest, T3 regulates the energy dissipation related to proton leakage. Basal mitochondrial proton leakage accounts for about $25 \%$ of whole-body resting energy expenditure; therefore, the modulation of proton leakage by T3 may result in significant control of total body energy expenditure. In this context, the authors in [28] have shown that mitochondrial PTP gating could not be ascribed to T3-induced changes in the mitochondrial content of integral PTP components, that is, ANT, cyclophilin D, or VDAC, despite T3-induced increases in the expression of ANT and cyclophylin D. In vivo T3 treatment resulted in pronounced increase in liver mitochondrial Bax together with pronounced decrease in mitochondrial $\mathrm{Bcl} 2$, while hypothyroidism resulted in opposite effects that may be reversed by T3 [29]; mitochondrial free Bax induced by T3 results in a low-conductance PTP gating [28], the consequent proton leakage, and finally energy expenditure. The comprehension of the T3 transduction pathway that is involved in regulating mitochondrial energetics may offer novel targets for thyromimetics designed to modulate energy expenditure.

\section{Hypothyroidism and Heart Reperfusion Damage}

Heart reperfusion achieved through the implant of intracoronary stents or coronary by-passes in patients with ischemic heart disease is an obligatory therapy to maintain the myocardium viable after ischemia [30]. In this regard, sudden reoxygenation occurring when the vessels are opened causes considerable cell injury produced by the action of oxygen-derived reactive species, generated mainly by mitochondria $[31,32]$, associated to the $\mathrm{Ca}^{2+}$ overload which contributes to the myocardial insult. Although the controversial evidence of beneficial or deleterious effects of hypothyroidism in heart reperfusion has not been completed elucidated, several studies have shown an increased recovery of cardiac function compared to the observed in normal animals, as well as the protection against arrhythmias [33].

Increasing evidence suggests that heart injury by reperfusion results from mitochondrial $\mathrm{Ca}^{2+}$ overload, oxidative stress, adenine nucleotide depletion, elevated phosphate concentration, and depolarization which in turn induces the increase of nonspecific permeability [13]. As mentioned above, mitochondria from hypothyroid rats are resistant to permeability transition induced by $\mathrm{Ca}^{2+}$. In this sense, myocardial tissue from hypothyroid rats is also resistant to the damage exerted by reperfusion after an ischemic period [34]. As shown in Figure 2(a) during the ischemic period, hearts from control rats maintained sinusal rhythm; however, after removing the occlusion, reperfusion arrhythmias were evident and continued during $10 \mathrm{~min}$, up to the end of the experiment. Figure 2(b) shows ECG tracings from hypothyroid rats, in which the cardiac frequency remained unchanged during the ischemic period, as observed in the control rats. Remarkably, when blood flow was reestablished, no ventricular tachycardia was detected, and the hearts remained in sinus rhythm along the experiment.

Figure 2 shows the electrocardiogram (ECG) tracing from control and hypothyroid rats. Panel (a) illustrates the electric profile of a control rat, and Panel (b) of a hypothyroid rat.

The mechanisms involved in the protection remain under investigation, since they cannot been explained only by the metabolic changes induced by hypothyroidism, that is, low consumption of oxygen, higher myocardial glycogen levels, and slow decline of ATP levels during ischemia. Modification of signal transduction molecules seems to play an important role in the response to reperfusion of hypothyroid hearts. $\mathrm{PKC} \varepsilon$ is overexpressed, while phosphop46 and p54 JNK does not increase after I/R, suggesting that they play an important role in the hypothyroidisminduced cardioprotection [20]. In addition, a shift from $\alpha$ to $\beta$ myosin isoform expression and a lower expression of SERCA (sarco/endoplasmic reticulum $\mathrm{Ca}^{2+}$ ATPase) occurred in hypothyroid hearts. Further experiments are needed to completely understand the pathways involved in the protective effect of hypothyroidism in reperfusion.

\section{Innovative Mechanism to Explain Altered Kidney Function in Hypothyroidism}

The renal alterations observed in hypothyroidism are well known, among them: inability to produce maximally concentrated or diluted urine, reduced corticopapillary tissue concentration gradients for urea, impaired urinary acidification, and decreased glomerular filtration rate [35-37]. The abnormalities in glomerular hemodynamics at the single nephron level are characterized by hypoperfusion and decreased permeability of the glomerular capillaries, resulting in a reduction of whole glomerular filtration rate [38]; these hemodynamic changes suggest the presence 

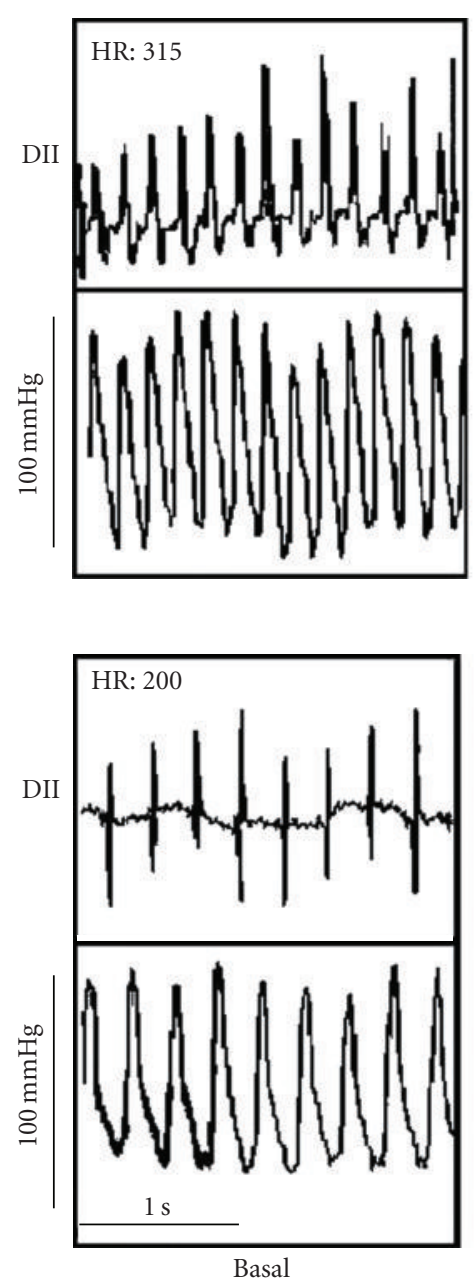

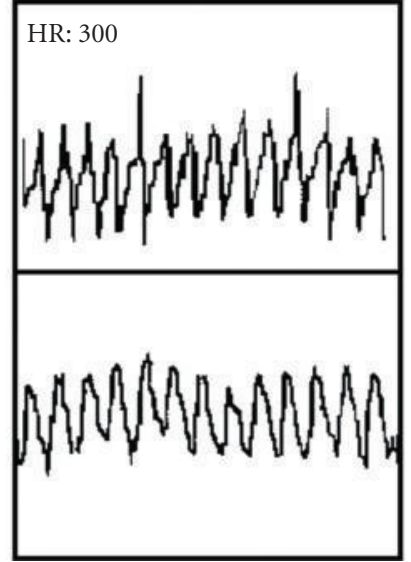

(a)

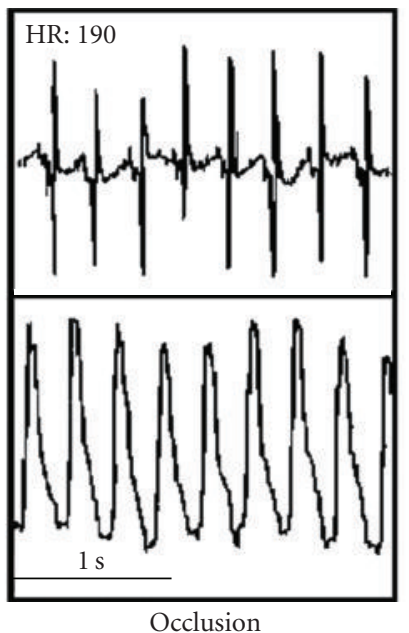

(b)
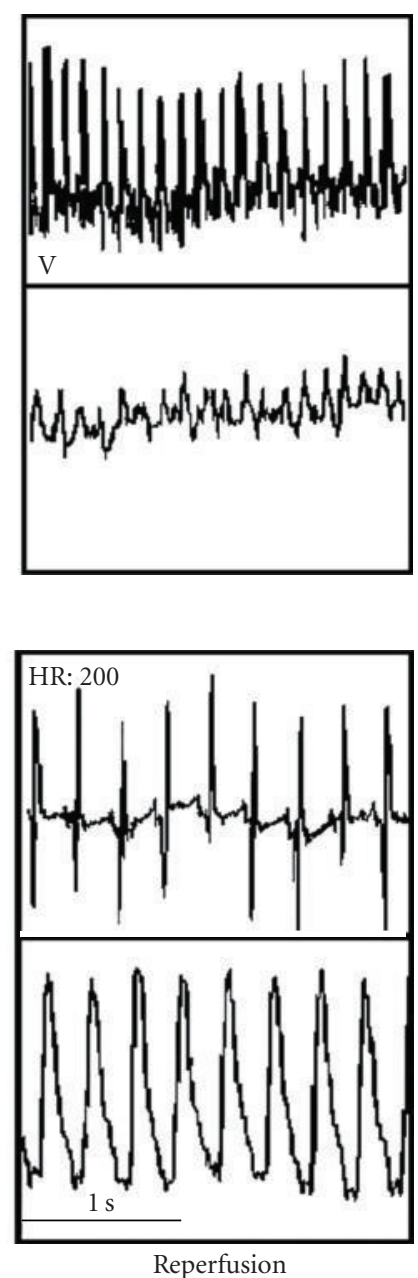

Figure 2: Electrocardiogram of control (a) and hypothyroid (b) rats (modified from [34]). See text for explanation.

of vasoconstrictor compounds influencing renal function, among them, participation of angiotensin II has been suggested [39]. However, the alterations of ATP metabolism play a greater role in the physiopathological mechanisms involved in the abnormalities of renal function in hypothyroidism. In the presence of an abnormal nucleoside metabolism characterized by a low production of ATP such as in hypothyroidism, ATP degradation leads to a decreased adenosine $(\mathrm{ADO})$ production. To this regard, ADO has been implicated in the regulation of glomerular filtration rate because of its unique vasoactive properties [40-42]; the nucleoside induces systemic vasodilation and renal vasoconstriction. We demonstrated that administration of an $\mathrm{ADO}$ receptors antagonist (PSPX) or administration of exogenous ADO reverts the renal vasoconstriction of rats with acute hypothyroidism (Figures 3 and 4) induced by surgical thyroidectomy with parathyroid reimplant [38].

The observation that in hypothyroid rats the response in renal hemodynamics to $\mathrm{ADO}$ administration is opposite to the changes observed in sham-operated rats is remarkable; these results suggest that ADO production is low and stimulates preferentially ADO A1 receptors, which mediate vasoconstriction.

Indeed, when a dose-response curve of single nephron glomerular filtration rate was obtained with intra-arterial infusion of adenosine, the difference in the response between sham-operated (Sham) and thyroidectomized (HTX) rats was clearly demonstrated; single nephron glomerular rate (SNGFR) decreased progressively with the various doses of adenosine, as is well recognized [35-39]; in contrast, in the HTX rats, there was an initial decrease of SNGFR, followed by no changes and a marked increase with the highest dose of adenosine, supporting the notion that ADO was low in the kidney of HTX, and that increased concentrations of adenosine were able to activate $\mathrm{ADO} \mathrm{A} 2$ receptors that induce vasodilation.

When ADO tissue content was measured in the kidneys of Sham and HTX rats, the later had a very low content of the nucleoside (Figure 5). These responses in glomerular hemodynamics are in accordance with the fact that high affinity ADO A1 receptors are preferentially activated by low concentrations of $\mathrm{ADO}$, and the low affinity $\mathrm{ADO} 2$ receptors 


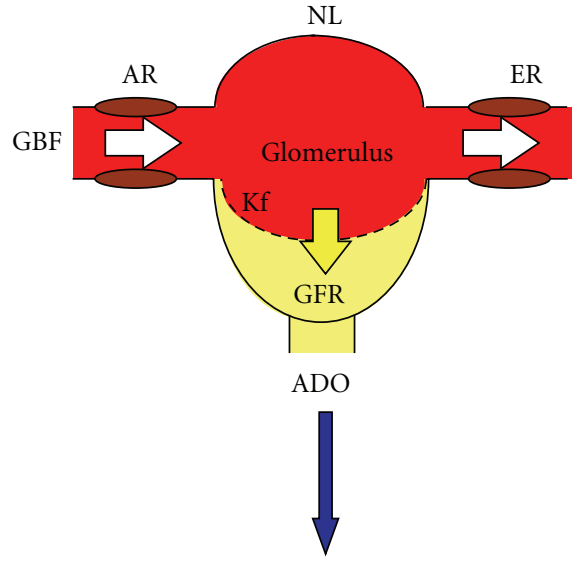

(a)

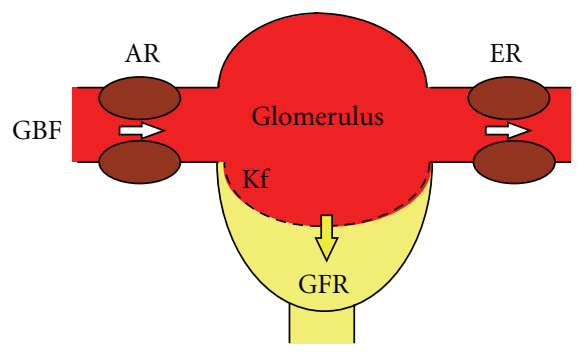

(c)

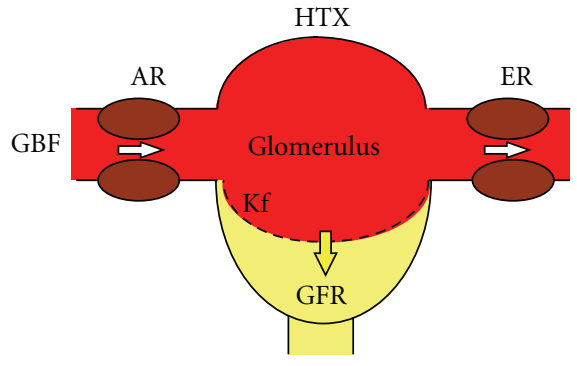

$\mathrm{ADO}$

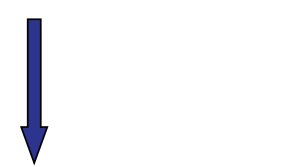

(b)

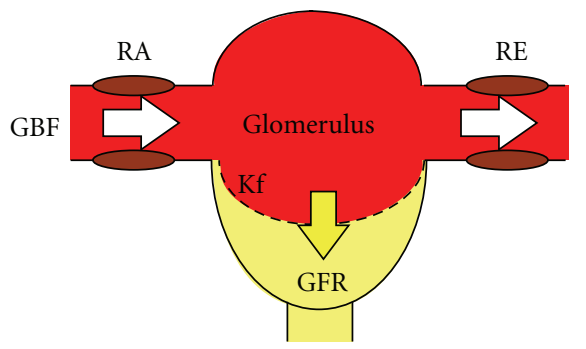

(d)

Figure 3: Effect of adenosine (ADO) on glomerular hemodynamics in normal and (NL) and hypothyroid (HTX) rats. (a) The balance of glomerular blood flow (GBF), the afferent and efferent resistances (AR, ER, resp.), and the permeability of the glomerular capillary membrane (Kf) maintain a normal glomerular filtration rate (GFR). (c) Administration of exogenous adenosine to normal rats produces an increase in afferent and efferent resistances, which in turn result in decreased glomerular blood flow and glomerular permeability; as a final consequence, the glomerular filtration rate diminishes. (b) Glomerular hemodynamics of the hypothyroid kidney. There is a glomerular vasoconstriction due to an increase in afferent and efferent resistances, a decrease in glomerular blood flow, and permeability of the glomerular capillary membrane, which results in a decreased glomerular filtration rate. (d) When exogenous adenosine is administrated to HTX rats, glomerular hemodynamics and GFR reach values near to normal. White arrows are indicative of magnitude of AR or ER, whereas yellow arrows represent the magnitude of the glomerular filtration rate.

are activated by high concentrations of the nucleoside (Figure 5).

Hypothyroidism induces important changes in the enzymes involved in the metabolism of adenosine, and these changes seem to be organ specific; thus, an increase in $5^{\prime}$ nucleotidase activity and a decrease in adenosine kinase have been reported in brain tissue of hypothyroid rats [43]. Moreover, 5' -nucleotidase and adenosine deaminase activities in brown and white adipocytes have been shown to decrease [44] associated with a lower adenosine content [45]; these cells develop an enhanced sensitivity to the nucleoside. These findings are in agreement with the results obtained on renal hemodynamics in the kidney of hypothyroid rats in our study.

\section{Participation of Adenosine Receptors in the Regulation of Renal Function in Hypothyroidism}

To further investigate the mechanisms of renal vasoconstriction observed in hypothyroid rats, we performed binding studies for A1 and A2 adenosine receptors in the kidneys from hypothyroid rats [46]. We should point out that the response of receptors to an agonist or antagonist depends on both the number and affinity of the receptors. We were able to demonstrate two binding sites, a high $\left(K_{H}\right)$ and a low $\left(K_{L}\right)$ affinity for adenosine A1 and A2 receptors with the radioligands $(3 \mathrm{H}) \mathrm{CPA}$ (ADO A1 agonist) and $(3 \mathrm{H})$ CGS21680 (ADO A2 agonist) in the renal cortex and medulla of Sham and hypothyroid rats. In the renal cortex from hypothyroid rats, no differences seem to exist in the highspecificity state of the A1 receptor; however, significant lower values were observed in the low-specificity state for affinity and number of A1 receptors [46]. In contrast, at the $\mathrm{A} 2$ receptors, an increase in affinity and number of the $K_{H}$ receptors was observed, with a decrease in affinity and number of the $K_{L}$ A2 receptors. These results are in agreement with the cortical renal vasoconstriction observed in hypothyroid rats, as well as the vasodilator response to adenosine infusion [37].

The collecting ducts and loop of Henle of the juxtamedullary nephrons are located mainly in the outer strip of the medulla. The fine regulation of blood flow and 
solute reabsorption occur in these structures [47], and the medullary segments regulate the concentration of urine. A1 adenosine receptors are mainly in the low-affinity state of the outer and inner medulla in the hypothyroid kidney, but both low and high affinity $\mathrm{A} 2$ receptors increase and predominate in the outer and inner medulla. In hypothyroidism, an inability to achieve either maximal concentration or dilution of urine is recognized [48-51]. A2 adenosine receptors have been proposed to have a role in the regulation of the vasa recta and transport mechanism in the medullary segments of the nephron [52]. Thus, the changes in A1 and A2 adenosine receptors in the medullary segments may increase blood flow in the vessels, which results in a washout of interstitial solutes, decreasing medullary tonicity, thereby producing an impairment in the concentration of tubular fluid and a decrease in sodium and water reabsorption, [52-54]. Thus, the changes in adenosine receptors in the renal medullary segments from hypothyroid rats may contribute to induce an inability to concentrate urine and a decrease in tubular reabsorption, as observed in hypothyroidism.

\section{Regulation of Renal Nitric Oxide Production by Adenosine in Hypothyroidism}

It has been suggested that, in smooth muscle, the vasodilation produced by adenosine may implicate nitric oxide production (NO) [55]. In this regard, the vasodilator action of $\mathrm{ADO}$ A2 analogs in coronary vasculature is mediated by $\mathrm{NO}$ production, since A2 receptors are expressed in the endothelial cells [56]. In isolated renal arteries, N6-cyclopentyl adenosine (ADO A1 agonist) and 5'-N-ethylcarboxamido adenosine (ADO A2 agonist) induce vasodilation by activation of ADO receptors located in the endothelium and in smooth muscle, the latter involving NO release [56]. Furthermore, ADO stimulates NO production in endothelial cell culture [57]. However, controversial evidence has been obtained regarding the effects of ADO on intact aortas and aortic endothelium-denuded preparations contracted with phenylephrine [58].

In the kidney, the release of $\mathrm{NO}$ increases, opposing the vasoconstrictor effects of ADO; the same mechanism occurs with various vasoconstrictor substances such as angiotensin II and norepinephrine [59]; however, interaction between $\mathrm{ADO}$ and NO production has not been completely elucidated. As mentioned above, in hypothyroidism, exogenous adenosine vasodilates the kidney instead of exerting the known vasoconstrictive effect [38]. Thus, it is possible that nitric oxide might be involved in this effect. We have demonstrated that whole glomerular filtration rate (GFR) decreased in response to exogenous ADO in Sham rats; in contrast, in hypothyroid rats, the baseline of whole GFR was significantly lower than in the Sham group and increased during administration of exogenous ADO. However, ADO administration stimulated nitrite-nitrate $\left(\mathrm{NO}_{2}{ }^{-} / \mathrm{UNO}_{3}{ }^{-}\right)$ production in both normal (NL, or Sham) and HTX groups, but this effect was significantly higher in the HTX rats (3.6 times increase in HTX versus 2.2 times increase in Sham). To further study the effects of ADO in the HTX kidney, ADO A1 receptors were blocked with a specific receptor blocker
(DPSPX), which increased GFR in both groups; urinary excretion of $\mathrm{NO}_{2}{ }^{-} / \mathrm{UNO}_{3}{ }^{-}\left(\mathrm{UNO}_{2}{ }^{-} / \mathrm{UNO}_{3}{ }^{-}\right)$increased in NL and HTX groups, but in the HTX rats, it reached the same values as in Sham rats. These results suggest a role of ADO A2 receptors in the increased GFR and $\mathrm{UNO}_{2}{ }^{-} / \mathrm{UNO}_{3}{ }^{-}$in $\mathrm{NL}$ and HTX rats. Nevertheless, the dependency of GFR on NO production seems to be very important in hypothyroidism. To support the evidence that the increased $\mathrm{UNO}_{2}{ }^{-} / \mathrm{UNO}_{3}{ }^{-}$ induced by $\mathrm{ADO}$ and the ADO A1 blocker was actually due to changes in NO production, NO synthase was inhibited with L-NAME. L-NAME + ADO in NL rats decreased GFR and prevented the increase in $\mathrm{UNO}_{2}{ }^{-} / \mathrm{UNO}_{3}{ }^{-}$; in HTX rats, GFR as well as $\mathrm{UNO}_{2}{ }^{-} / \mathrm{UNO}_{3}{ }^{-}$remained unchanged, since L-NAME completely prevented the renal vasodilator effects of ADO (Figure 6) [60].

As it can be observed, adenosine markedly stimulates the production of NO in the hypothyroid rats, which is associated with an increase in glomerular filtration rate; this effect is completely blocked when L-NAME is coinfused with adenosine. These results are in agreement with the results obtained by Quesada et al. [61] who show that nitric oxide synthase activity remains within the normal range in the cortex and medulla from hypothyroid rats, which explains the increased $\mathrm{NO}$ results obtained with ADO in the hypothyroid rats and supports the notion that in hypothyroidism the production of NO is regulated by adenosine. In contrast, Moreno et al. demonstrated, in the isolated kidney of hypothyroid rats, that the vascular reactivity of the kidney is reduced to NO donors, and it is insensitive to NO blockade; however, renal function was not evaluated in this study [62].

\section{Participation of Adenosine in the Regulation of Vascular Relaxation in Hypothyroidism}

A limited number of studies have investigated systemic vascular relaxation under hypothyroid conditions; the evidence available indicates no alterations in response to acetylcholine (Ach) or $\mathrm{CaCl}_{2}$ in aortic vessels $[36,63]$; however, the vasodilation mediated by ADO has not been completely elucidated. In this regard, it has been suggested that the aorta has heterogeneous populations of A1 and A2 ADO receptors [64], which inhibit or stimulate adenylate cyclase, respectively. A3 receptors [65] activate guanylate cyclase and mediate cellular responses by inducing nitric oxide production [66]. In this regard, it has been clearly demonstrated that HTX aortas show a reduced contractile response to noradrenaline (NA) or phenylephrine (PE) when compared to normal arteries (NL) [67-69], indicating a lower response to receptor-mediated vasoconstrictors and nonreceptor-mediated smooth muscle $(\mathrm{KCl})$ in HTX vessels.

Adenosine has been used as a physiological agonist to investigate the activation of various receptors, and CPA ( $\mathrm{N}^{6}$-cyclopentyladenosine) and NECA $\left(5^{\prime}-\right.$ ethylcarboxamidoadenosine), the former a specific agonist for $\mathrm{A} 1$, and for $\mathrm{A} 2 \mathrm{a}, \mathrm{A} 2 \mathrm{~B}$, and $\mathrm{A} 3$ receptors the latter have been used to investigate the participation of those receptors in vascular regulation; more specific A2 (CGS21680) or A3 (IB-MECA) agonists have produced uncertain results in the NL aorta, suggesting activation of an undefined receptor 


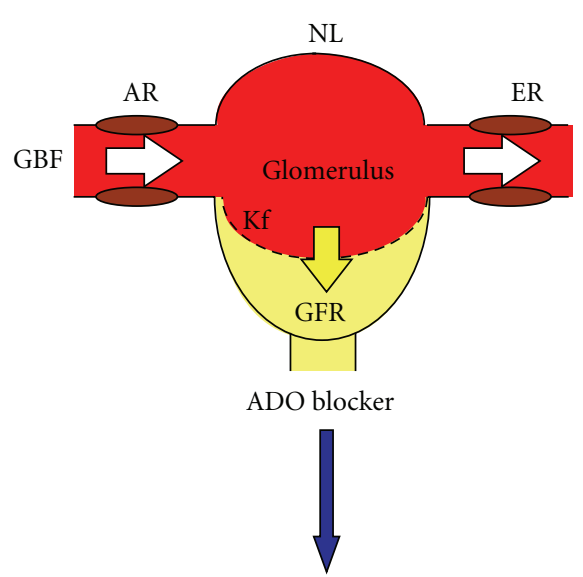

(a)

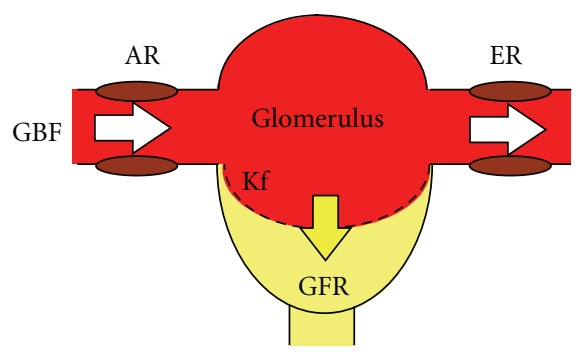

(c)

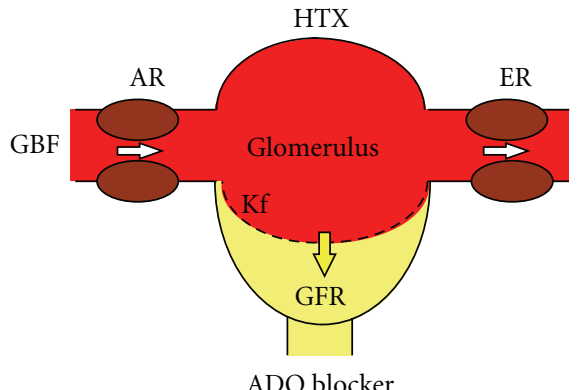

ADO blocker

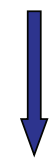

(b)

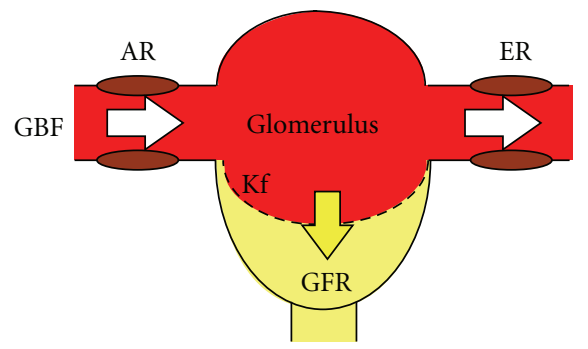

(d)

FIGURE 4: Response to an adenosine (ADO) blocker (PSPX) in glomerular hemodynamics from normal (NL) and hypothyroid (HTX) rats. (a) The balance of glomerular blood flow (GBF), the afferent and efferent resistances (AR, ER, resp.), and the permeability of the glomerular capillary membrane (Kf) maintain a normal glomerular filtration rate (GFR). (c) Since normal glomerular hemodynamics is not importantly regulated by adenosine, the administration of an adenosine blocker does not modify the GFR. (b) In contrast, renal vasoconstrictions are observed under hypothyroid conditions. (d) The administration of an adenosine blocker completely reverses the alterations of glomerular hemodynamics in the hypothyroid kidney. White arrows are indicative of magnitude of AR or ER, whereas yellow arrows represent the magnitude of the glomerular filtration rate.

[64]. We studied the effect of $\mathrm{ADO}$ and $\mathrm{ADO}$ agonists, CPA and NECA, in aortic rings from HTX rats, and they clearly produced an increase in the maximal relaxation in NA-PE-, and $\mathrm{KCl}$-contracted rings from the HTX group as compared with normal vessels (Figure 7).

The A2 ADO receptors are the most abundant in the normal rat thoracic aorta [70], and they are located in both endothelium and smooth muscle cells. However, the predominant action of ADO seems to be mediated by direct smooth muscle receptor activation [67]; the potency of responses, NECA $>\mathrm{CPA}>\mathrm{ADO}$ in NL and HTX aortas, found in our study was consistent with this report; although the vasodilator response to ADO has not been explored in hypothyroidism, our results suggest a higher sensitivity of the receptors or an increase in number by an upregulation mechanism [71].

It is generally accepted that vasodilation is endothelium dependent and is mediated by NO in normal vessels [71]. Some studies have demonstrated that the vasodilator effects of ADO are mediated by NO production [72]. Certainly, this is the main mechanism mediating vasodilator responses in some vessels, such as the guinea pig coronary vasculature [73], rat mesenteric arteries [74], and renal arteries [75]. In general, the vasodilator effect of ADO has been considered partially endothelium dependent [58], but controversial evidence has been found for the ADO stimulatory effects on NO production of endothelial cell cultures [73, 76]. As we observed in our experiments, L-NAME did not significantly block the effects of ADO and its analogs in NA and PE-contracted NL or HTX aortic rings; in contrast, when the effect of $\mathrm{A} 1$ and $\mathrm{A} 2 \mathrm{ADO}$ receptor antagonist (DPSPX) was evaluated, blocking of ADO receptors with high concentrations of DPSPX significantly reduced the effects of ADO on HTX vessels but had a small contribution in decreasing the vasodilation in NL vessels. The vasodilator response in the HTX rings was not completely inhibited by DPSPX, suggesting the presence of A3 ADO receptors, since these receptors are resistant to blockade with several xanthine derivatives, among them DPSPX [77, 78]. The inhibition of relaxation with DPSPX in HTX aortas greatly supports the hypothesis that ADO receptors mediate the relaxation response under these conditions. It has been demonstrated that $\mathrm{A} 2 \mathrm{ADO}$ receptors located in the endothelial cells induce an age-dependent vasodilatation response through generation of NO, which stimulates cyclic GMP in aortic rings [79]. HTX rats may express ADO 
ADO tissue content, $\mathrm{nmol} / \mathrm{g}$ wet weight

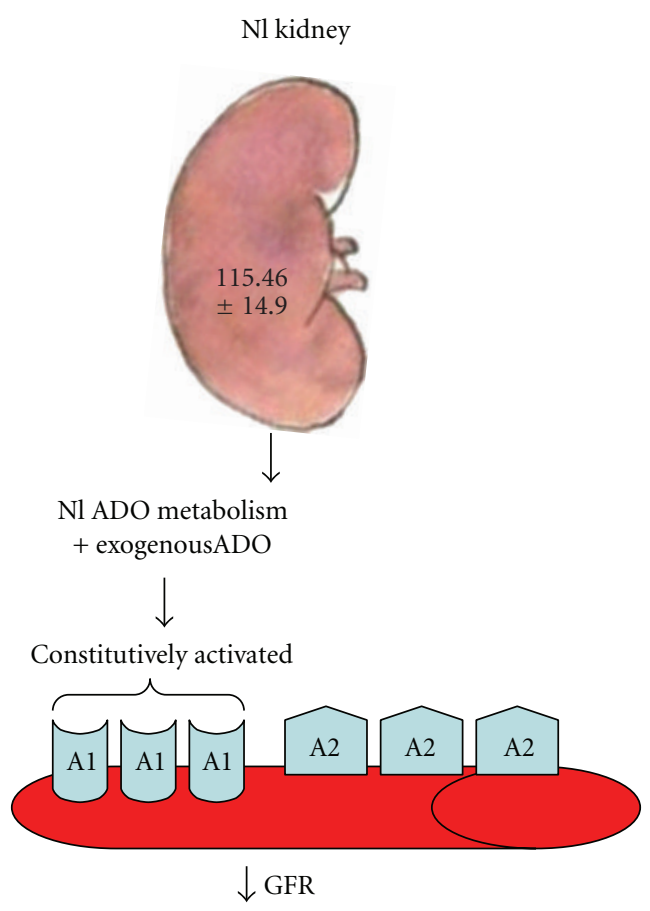

(a)
ADO tissue content, $\mathrm{nmol} / \mathrm{g}$ wet weight
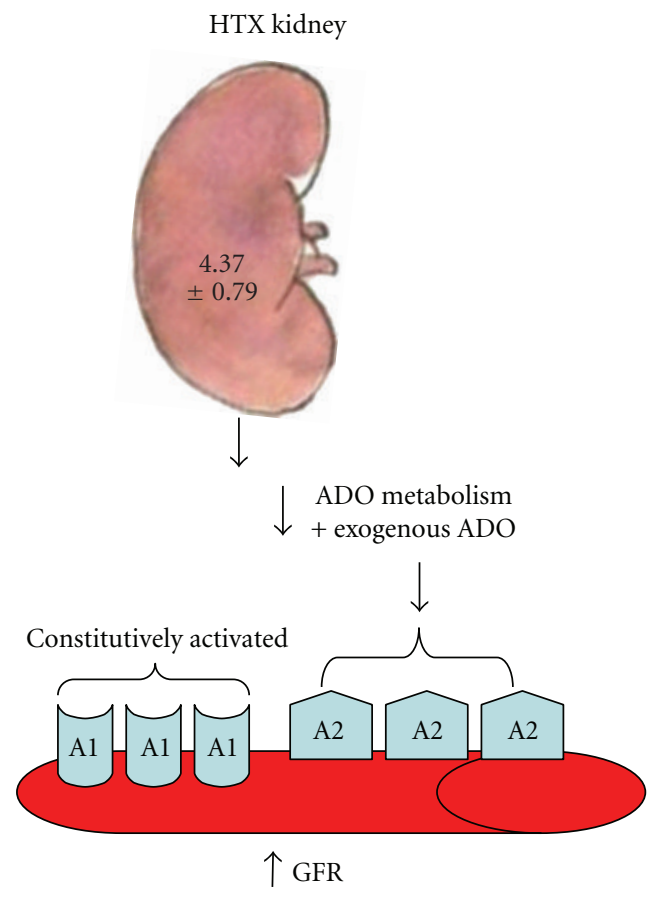

(b)

FIGURE 5: The adenosine tissue content is markedly affected by hypothyroidism; under normal conditions, the metabolism of adenosine is very fast, thus the administration of exogenous adenosine within the $\mu$ molar range activates preferentially the high-affinity A1 receptors and induces vasoconstriction (a). In contrast, under hypothyroid conditions, since the metabolism of adenosine is abnormally low, exogenous adenosine reaches concentrations high enough to activate adenosine A2 receptors and induce vasodilation, (b).

receptors in a similar manner to that of aged rats. Thus, it is quite possible that $\mathrm{ADO}$ receptors located in the smooth muscle mediate relaxation in the HTX model. The ADOmediated vasodilation increase in aortic rings of HTX rats suggests a novel mechanism in which ADO receptors may be involved in regulating the vascular tone in hypothyroidism [67].

In summary, hypothyroidism is characterized by changes in adenosine receptor number and sensitivity in the kidney, which results in renal vasoconstriction and induces an impairment in the ability to concentrate or dilute urine. Nitric oxide production in the kidney of hypothyroid rats is mediated by ADO receptors and seems to play an important role in the regulation of glomerular filtration rate and renal hemodynamics. In addition, adenosine receptors play an important role in the regulation of vascular tone in the hypothyroid rat; however, at least in the aorta, the effect is directly mediated by $\mathrm{ADO}$ receptors with a minor contribution of NO.

\section{Hypothyroidism and Intravascular Metabolism of Lipoproteins}

Atherosclerosis is a common feature in hypothyroidism. The early stages of the atherogenic process are represented in Figure 8; high-density lipoproteins (HDLs) play a protective role by promoting cholesterol efflux and improving endothelial function [80]. Moreover, HDLs have antioxidant [8183 ], antithrombotic [84], and anti-inflammatory properties $[85,86]$. HDLs stimulate the synthesis of nitric oxide by the endothelium [84] and contribute to the endothelial function through the enzyme paraoxonase-1 (PON1) [81-83]. This enzyme catalyzes the conversion of the proatherogenic LDL lipoperoxides to the corresponding lipohydroxides; the former generated by the reactive oxygen species produce severe damage to the endothelium, and the latter are biologically innocuous [72].

In this context, thyroid hormones have been extensively associated with atherosclerosis; overt hypothyroidism induces high plasma levels of low-density lipoprotein (LDL) cholesterol, diastolic hypertension, increased coagulability, and vascular smooth muscle impaired function [87]. There is substantial epidemiological support for the direct relationship between hypothyroidism and atherosclerosis. In a cross-sectional analysis of the Rotterdam study [80], women with subclinical hypothyroidism had a significantly higher prevalence of aortic atherosclerosis and a higher prevalence of myocardial infarction than euthyroid women, after adjustment for age, body mass index, high-density lipoprotein (HDL), blood pressure, and smoking status. Women with antibodies to thyroid peroxidase in the absence of thyroid function test abnormalities had a similar prevalence of 
NL kidney

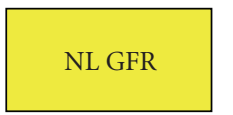

$\downarrow \downarrow$ GFR

ADO

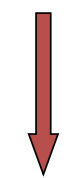

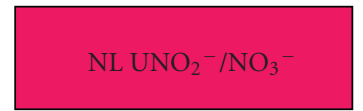

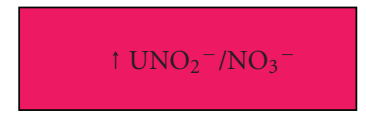

(a)
HTX kidney
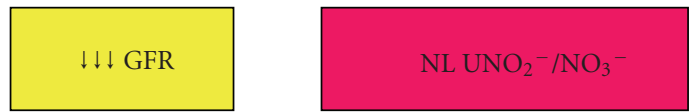

ADO

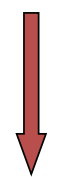

NL GFR

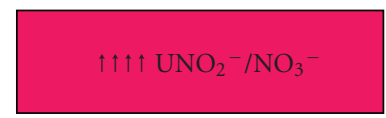

(b)

FIgURE 6: The effect of adenosine on urinary excretion of $\mathrm{NO}_{2}{ }^{-} / \mathrm{NO}_{3}{ }^{-}\left(\mathrm{NO}_{2}{ }^{-} / \mathrm{NO}_{3}{ }^{-}\right)$. Exogenous adenosine induces a decrease of the glomerular filtration rate (GFR) in normal (NL) kidneys and slightly increases the urinary excretions of nitrites. In contrast, in the hypothyroid (HTX) kidneys, despite the vasoconstriction, the urinary excretion of nitrates is within the normal range. When exogenous adenosine is administrated to HTX kidney, the glomerular filtration rate returns to normal values but is associated with a marked increase in the $\mathrm{UNO}_{2}{ }^{-} / \mathrm{NO}_{3}{ }^{-}$, suggesting that this effect is mediated by nitric oxide.

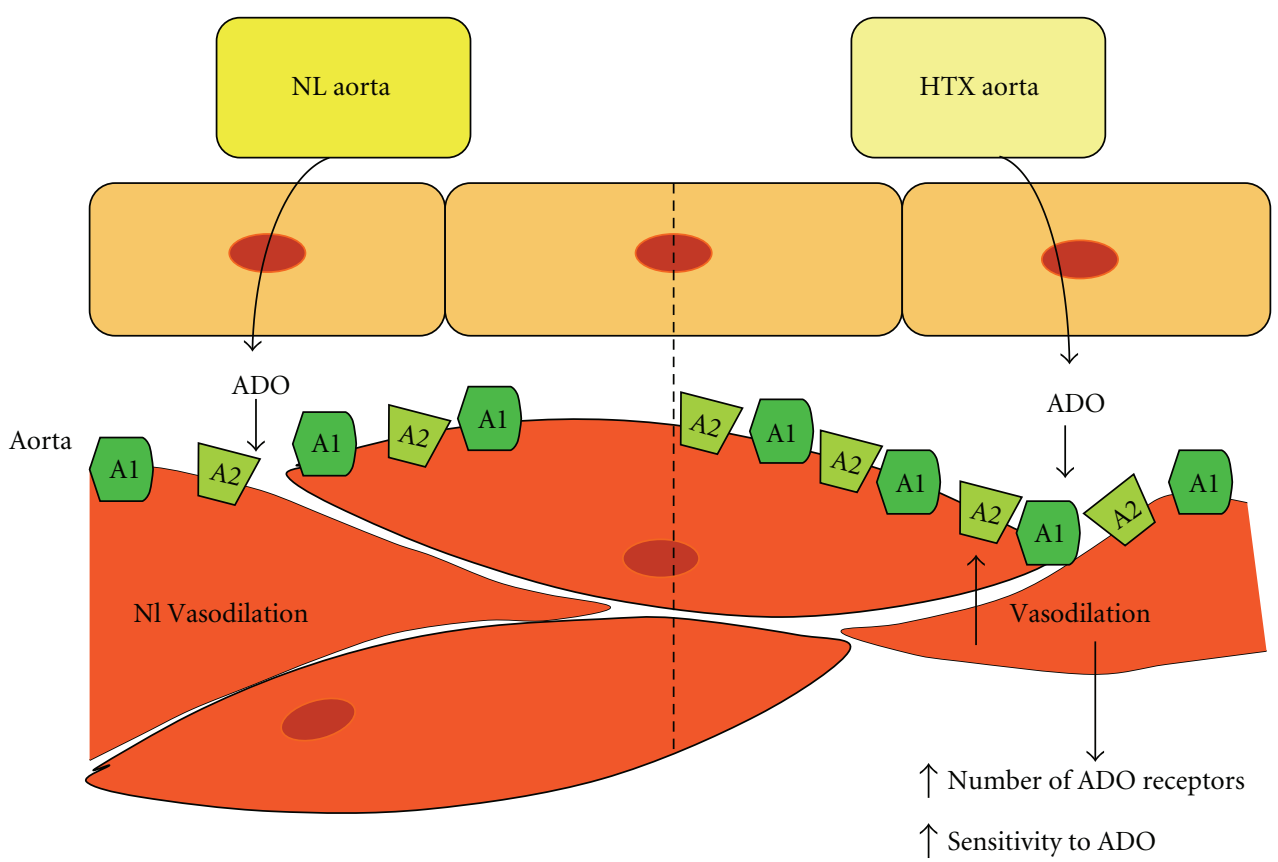

FIGURE 7: In spite of a similar norepinephrine-induced vasoconstriction of the aortic rings from normal (NL) and hypothyroid (HTX) rats, adenosine- (ADO-) induced vasodilation is markedly higher in the HTX aortic rings. Increased number of adenosine receptors or a higher sensitivity to the receptors to exogenous adenosine may explain the higher sensitivity of HTX aortic rings to ADO.

aortic atherosclerosis and myocardial infarction as euthyroid women without antibodies, suggesting that the increased atherosclerosis was mediated by relative T4 deficiency rather than immune dysfunction.

In agreement with this notion, the Whickham Survey revealed an association between incident ischemic heart disease (IHD) events and IHD-related mortality with subclinical hypothyroidism over a 20-year followup [88, 89]. However, subsequent treatment of subclinical hypothyroidism with levothyroxine attenuated IHD-related morbidity and mortality, supporting the concept that T4 plays a direct role on the protection against coronary events. Besides, in a recent meta-analysis, it was suggested that subclinical hypothyroidism is associated with an increased risk of congestive heart failure among older adults with a TSH level of $7.0 \mathrm{mIU} / \mathrm{L}$ or greater, but not with coronary heart disease, stroke, peripheral arterial disease, or cardiovascular-related mortality [90].

The molecular basis of the protective role of thyroid hormones against atherosclerosis is mainly related with 


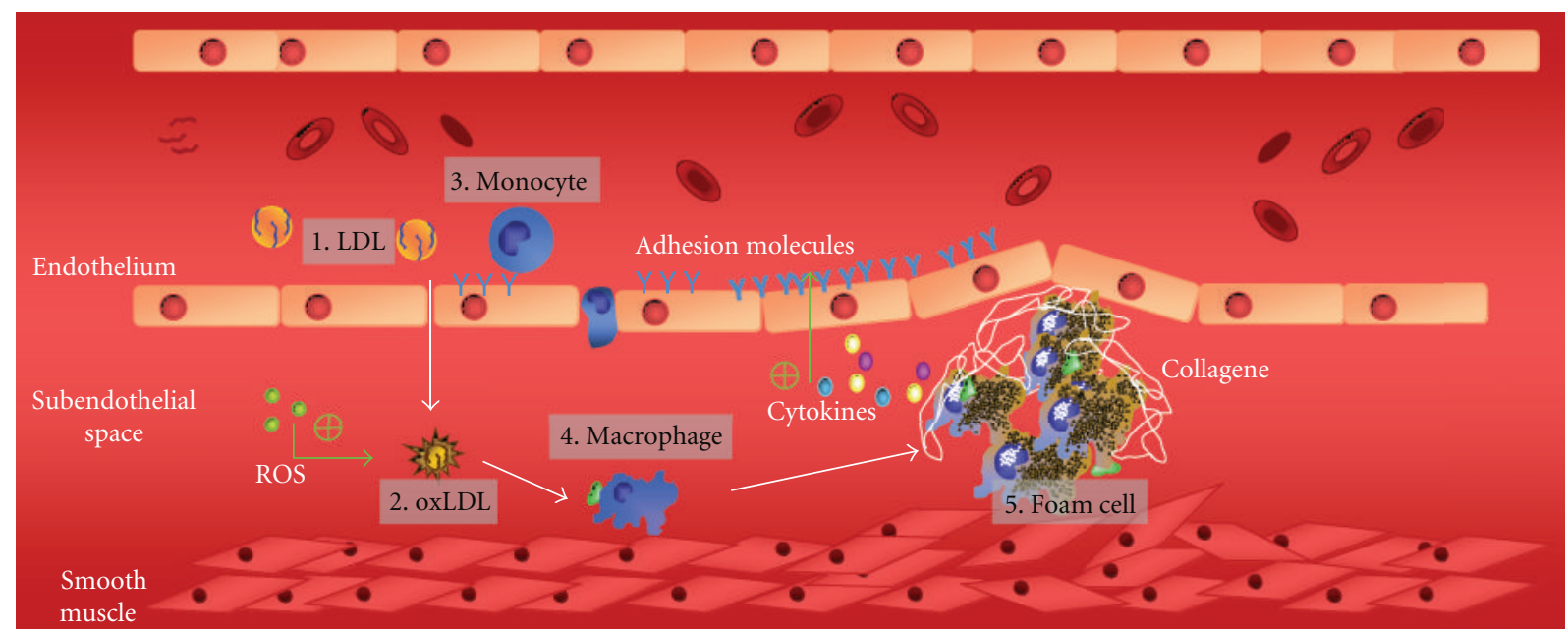

Figure 8: Early stages of the atherogenic process. (1) Low-density lipoproteins (LDLs) reach the subendothelial space. (2) LDLs become oxidized by reactive oxygen species (ROS). (3) Oxidized LDLs act as chemotactic molecules for monocytes. (4) Monocytes differentiate in macrophages within the subendothelial space (5) Macrophages further phagocyte oxidized LDL with the consequent lipid accumulation in their cytoplasm, originating a foam cell that favours an inflammatory response by stimulating the endothelial expression of adhesion molecules.

the regulation of the intravascular metabolism of lipoproteins. Elevated levels of total cholesterol, LDL-cholesterol, and apo B are well-documented features of hypothyroidism [91]. The metabolic origin of such abnormalities has been described in previous studies; propylthiouracilinduced hypothyroidism in rats resulted in nearly 50\% decrease of LDL receptor mRNA levels in the liver. In agreement with these observations, LDL receptor mRNA levels increase more than $50 \%$ in euthyroid rats supplemented with T4 [92]. Therefore, decreased LDL receptor expression explains the low LDL clearance observed in cultured human skin fibroblasts [93]. Low LDL clearance was also observed in early studies using isotopically labeled lipoproteins in humans [94] and reviewed elsewhere [87]. These findings were supported by an "in vivo" study in a hypothyroid woman whose receptor-mediated LDL catabolism was reduced, compared with euthyroid controls, with significant improvement after T4 replacement therapy [95].

Further studies have established the molecular mechanisms that explain the regulation of LDL receptors by thyroid hormones; the promoter region of the gene coding for LDL receptor contains functional thyroid response elements. When the LDL receptor promoter was linked to a reporter gene and cotransfected with the $\beta 1$ isoform of the thyroid hormone receptor into a hepatic cell line, activity of the chimeric gene was observed when it was stimulated with T3 [96]. The specificity of different thyroid hormone receptors has been recently considered for drugs design, and they are discussed below.

Thyroid hormones also contribute to regulate the intravascular metabolism of high-density lipoproteins (HDLs) (Figure 9). HDLs, as other lipoproteins, are complex macromolecules composed ofphospholipids and free cholesterol on the surface and cholesteryl esters and triglycerides nonpolar lipids in the core. The physicochemical stability of HDL is guaranteed by several apolipoproteins; apo AI represents up to $70 \%$ of the protein mass whereas apo AII is the second more abundant protein of HDL. HDLs are secreted as discoid particles containing lipid-poor apo AI, and then they rapidly acquire phospholipids and unesterified cholesterol from tissues via the $\mathrm{ABC}-\mathrm{A} 1$ transporter to become spherical HDL particles (Figure 9). HDLs facilitate a process known as reverse cholesterol transport (RCT) in which cholesterol in peripheral tissues is delivered to these lipoproteins and ultimately returned to the liver for excretion in bile and feces.

The important role of HDL in the antiatherosclerotic process [81-86, 97] highlights the function of thyroid hormones on the intravascular metabolism of these lipoproteins. Clinical studies have reported conflicting results about HDL-cholesterol plasma levels in hypothyroidism; significantly lower HDL-cholesterol plasma concentrations were described when 52 patients with subclinical hypothyroidism and 18 with overt hypothyroidism were compared with 46 euthyroid controls [98]. Caron et al. [99] also reported that the HDL cholesterol level was significantly decreased among 29 women who had subclinical hypothyroidism, compared with 41 euthyroid women matched for age and metabolic parameters. Furthermore, a significant increase in HDL cholesterol plasma levels was observed after T4 therapy, which normalized the serum TSH concentration [99]. In contrast, other reports conclude that HDL cholesterol plasma levels are normal or even increased in human hypothyroidism [100-102] with a significant decrease after T4 treatment [103]. The effect of T4 on HDL-C in this study was independent from LDL receptor and CETP polymorphisms [103]. In addition, a controlled trial in which 66 women with 


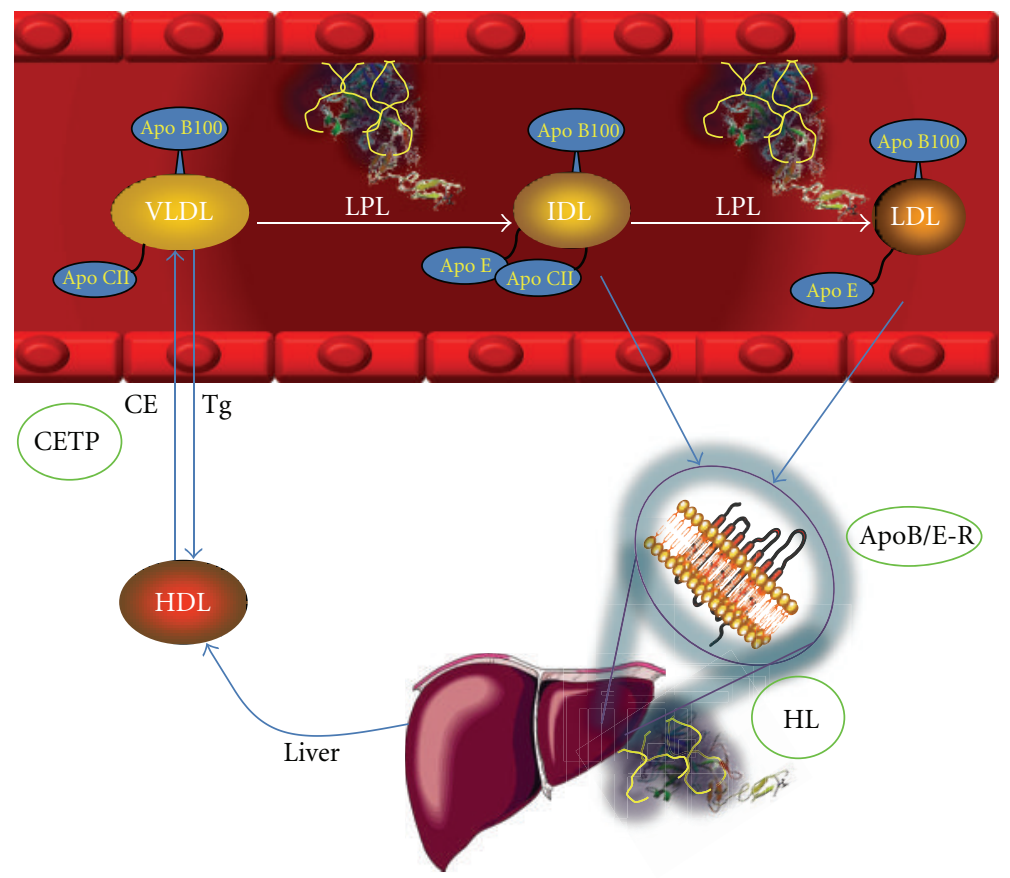

(a)

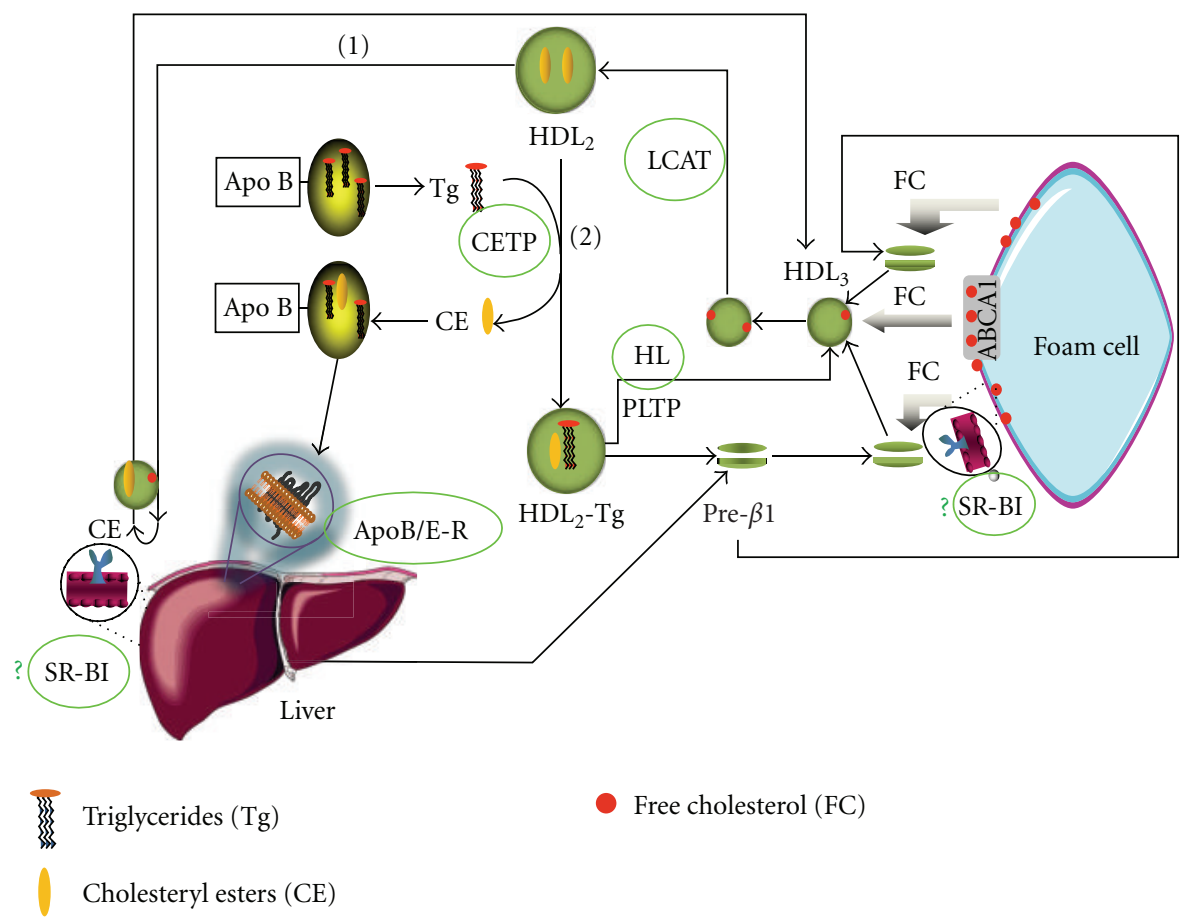

(b)

FIGURE 9: Intravascular metabolism of lipoproteins. (a) Very low-density lipoproteins (VLDLs) synthesized by the liver follow a lipolstic cascade up to the formation of low-density lipoproteins (LDLs), which are cleared from plasma by the apo B/apo E hepatic receptor (apoB/E$\mathrm{R})$. The cholesteryl esters transfer protein (CETP) facilitates the exchange of triglycerides from apo B containing lipoproteins to HDL and cholesteryl esters in the opposite sense. (b) High-density lipoproteins (HDL) pick up cholesterol from peripheral tissues, including the foam cells. HDL cholesterol becomes esterified by the activity of the lecithin:cholesterol acyl transferase (LCAT). Cholesteryl esters are cleared from plasma by the hepatic scavenger receptor class B, type I (SR-BI) or via CETP. Proteins involved in lipid metabolism that are regulated by thyroid hormones have been highlighted with green circles; low expression levels of SR-BI have not been reported (indicated by a green question mark). 
subclinical hypothyroidism were randomly assigned to T4 or placebo treatment found no significant change in either HDL cholesterol or apolipoprotein AI [104].

Hence, there is not a constant pattern concerning HDLcholesterol in hypothyroidism. Interestingly, several proteins related with HDL metabolism are affected by thyroid hormones (Figure 9(b)). Cholesteryl ester transfer protein (CETP) activity has been reported in human hypothyroidism [92, 93]; low CETP activity induces cholesterol accumulation in HDL particles that result in high HDL-C plasma levels [97]. In contrast, thyroidectomized rats, an animal species that lacks CETP activity, were characterized by a significant decrease of HDL-cholesterol and apo AI of about $26 \%$ and $23 \%$, respectively, as compared to controls. These paradoxical results suggest that the variability of HDL cholesterol among hypothyroid patients is not related to CETP activity.

Another key enzyme in intravascular HDL metabolism is LCAT (Figure 9(b)); the activity of this enzyme was found to be lower in hypothyroid rats than in controls [105], probably due to a decreased secretion of the protein by the hepatocyte [106]. It could be suggested that low LCAT activities are consistent with increased levels of HDL cholesterol, since free cholesterol is unable to continue its clearance from plasma. However, thyroidectomized rats exhibit low HDL cholesterol plasma levels as mentioned above, associated to low LCAT activities, suggesting a minimal contribution of this enzyme to abnormal HDL concentrations [106].

Low hepatic lipase (HL) seems to be another feature of hypothyroidism [105, 107]. HL catalyzes the hydrolysis of HDL triglycerides with the consequent remodeling of these lipoproteins towards smaller particles (Figure 9(b)). In agreement with this idea, HDL isolated from hypothyroid rats was significantly larger than those from euthyroid rats [108]. Since large HDLs are the best ligands of hepatic scavenger receptor B, class I (SR-BI), cholesteryl esters are cleared faster from plasma; the consequence of such enhanced interaction would be decreased HDL cholesterol plasma levels, as has been observed in hypothyroid rats $[105,108]$.

Another protein that regulates the metabolism of HDL and whose expression is likely controlled by thyroid hormones is the hepatic SR-BI [109]. SR-BI promotes the selective uptake of cholesteryl esters contained in HDL, particularly from the largest subclasses of these lipoproteins [110]. Studies with mice treated with GC-1, an analog of thyroid hormones with high affinity for the thyroid receptor beta induced an overexpression of SR-BI [109] which suggests that in hypothyroidism the synthesis of this protein is decreased. To our knowledge, low levels of SR-BI hepatic expression have not been described yet. However, HuescaGómez et al. described large HDL isolated from plasma of thyroidectomized rats [108]. This feature is consistent with a low expression of hepatic SR-BI since HDL become smaller after interacting with the receptor [110].

Reduced paraoxonase-1 activity paraoxonase-1 (PON1) activities is another important consequence probably related to the abnormal HDL structure in hypothyroidism [108]. PON1 is an enzyme that plays an important role against the toxicity of organophosphosphate pesticides [111], but it also catalyzes the conversion of lipoperoxides characteristic of the first stages of atherome formation to the corresponding lipohydroxides that are biologically innocuous [112]. In this context, PON1 has been considered as an antioxidant and antiatherogenic enzyme. PON1 is physically associated to HDL by hydrophobic interactions, the smallest HDL particles being the best carriers $[83,113]$. Since HDL size is increased during the hypothyroid status, low plasma levels of PON1 could be expected. Indeed, low PON1 plasma activities have been consistently reported in hypothyroid patients $[114,115]$ with significant increases after thyroxine replacement [115].

Low levels of thyroid hormones are also associated with an important decrease of apo AI catabolic rates of about 40\%, as demonstrated in thyroidectomized rats [108]. Such a low apo AI clearance was associated to very low synthesis rates of the protein, almost $60 \%$ lower than those of controls. The final balance of this metabolic behavior was a low plasma level of apo AI in hypothyroid rats [108]. This study clearly showed that hypothyroidism affects both synthesis and catabolism of the major component of HDL. Genetic and environmental factors may influence the final balance between the reduced synthesis and catabolism of HDL-apo AI in hypothyroid subjects; consequently, HDL plasma levels may be low, unchanged, and even increased, in function of the environmental and genetic background of each individual.

Aggressive reduction of LDL cholesterol is the basis of preventive cardiovascular care [116], but additional therapeutic approaches to reduce atherogenesis are still needed. Since thyroid hormones have a vast constellation of beneficial effects on lipoprotein metabolism, T4 analogs were considered to treat hypercholesterolemia. The apparent deleterious effects on heart function as well as the introduction of statins led to the discontinuation of clinical studies with T4 analogs in the 1970s. However, thyromimetic drugs are being explored to treat dyslipidemias (for a review, see [117]). Of particular interest have been the thyromimetics with high affinity for the thyroid receptor (TR) beta- 1 which is the predominant isoform of the hepatocyte that is almost absent in the heart $[117,118]$. In consequence, TR-beta- 1 agonists would improve lipoprotein metabolism without the negative impact on the heart [119]. The preliminary results with some thyromimetics are promising, and the final outcomes will define whether or not these drugs will become an alternative for statins.

In summary, high plasma levels of LDL cholesterol are a common feature of hypothyroidism. The metabolic basis of this abnormality is a low expression of the hepatic $\mathrm{LDL}$ receptor, since the gene coding for this protein is positively regulated by T4. Concerning the HDL, the profile is uncertain in hypothyroid subjects; proteins related to HDL metabolism such as HL, LCAT, possibly SR-BI, and the main constituent of HDL, apo AI, are expressed at lower levels under hypothyroid conditions. Consequently, the HDL metabolism is greatly affected in hypothyroidism, but the impact of such metabolic impairment on HDL cholesterol plasma levels is variable. On the basis of the positive 
influence of thyroid hormones on lipoprotein metabolism, thyromimetic drugs with specificity for TR-beta-1 are very promising for the treatment of dyslipidemia.

\section{References}

[1] I. E. Scheffler, Mitochondria, Whiley and Sons, New Jersey, NJ, USA, 2nd edition, 2008.

[2] G. Paradies and F. M. Ruggiero, "The influence of hypothyroidism on the transport of phosphate and on the lipid composition in rat-liver mitochondria," Biochimica and Biophysica Acta, vol. 1070, no. 1, pp. 180-186, 1991.

[3] G. Paradies, F. M. Ruggiero, G. Petrosillo, and E. Quagliariello, "Enhanced cytochrome oxidase activity and modification of lipids in heart mitochondria from hyperthyroid rats," Biochimica et Biophysica Acta, vol. 1225, no. 2, pp. 165-170, 1994.

[4] S. G. Robles, M. Franco, C. Zazueta et al., "Thyroid hormone may induce changes in the concentration of the mitochondrial calcium uniporter," Comparative Biochemistry and Physiology B, vol. 135, no. 1, pp. 177-182, 2003.

[5] P. Schönfeld, M. R. Wiêckowski, and L. Wojtczak, "Thyroid hormone-induced expression of the ADP/ATP carrier and its effect on fatty acid-induced uncoupling of oxidative phosphorylation,” FEBS Letters, vol. 416, no. 1, pp. 19-22, 1997.

[6] R. Mangiullo, A. Gnoni, F. Damiano et al., "3,5-diiodoL-thyronine upregulates rat-liver mitochondrial $\mathrm{F}_{\mathrm{o}} \mathrm{F}_{1}$-ATP synthase by GA-binding protein/nuclear respiratory factor2," Biochimica et Biophysica Acta, vol. 1797, no. 2, pp. 233-240, 2010.

[7] J. Kvetny, L. Wilms, P. L. Pedersen, and J. Larsen, "Subclinical hypothyroidism affects mitochondrial function," Hormone and Metabolic Research, vol. 42, no. 5, pp. 324-327, 2010.

[8] G. M. Hatch, "Cardiolipin: biosynthesis, remodeling and trafficking in the heart and mammalian cells," International Journal of Molecular Medicine, vol. 1, no. 1, pp. 33-41, 1998.

[9] D. L. Pehowich, "Hypothyroid state and membrane fatty acid composition influence cardiac mitochondrial pyruvate oxidation," Biochimica et Biophysica Acta, vol. 1235, no. 2, pp. 231-238, 1995.

[10] G. Paradies, F. M. Ruggiero, G. Petrosillo, and E. Quagliariello, "Stimulation of carnitine acylcarnitine translocase activity in heart mitochondria from hyperthyroid rats," Federation of European Biochemical Societies Letters, vol. 397, no. 2-3, pp. 260-262, 1996.

[11] G. Paradies, F. M. Ruggiero, G. Petrosillo, and E. Quagliariello, "Alterations in carnitine-acylcarnitine translocase activity and in phospholipid composition in heart mitochondria from hypothyroid rats," Biochimica et Biophysica Acta, vol. 1362, no. 2-3, pp. 193-200, 1997.

[12] K. Beyer and M. Klingenberg, "ADP/ATP carrier protein from beef heart mitochondria has high amounts of tightly bound cardiolipin, as revealed by $\mathrm{P}$ nuclear magnetic resonance," Biochemistry, vol. 24, no. 15, pp. 3821-3826, 1985.

[13] A. P. Halestrap and C. Brenner, "The adenine nucleotide translocase: a central component of the mitochondrial permeability transition pore and key player in cell death," Current Medicinal Chemistry, vol. 10, no. 16, pp. 1507-1525, 2003.

[14] N. Brustovetsky and M. Klingenberg, "Mitochondrial ADP/ATP carrier can be reversible converted into a large channel by $\mathrm{Ca}^{2+}$," Biochemistry, vol. 35 , no. 26, pp. $8483-$ 8488, 1996.
[15] E. Chávez, R. Moreno-Sánchez, M. E. Torres-Márquez et al., "Modulation of matrix $\mathrm{Ca}^{2+}$ content by the ADP/ATP carrier in brown adipose tissue mitochondria. Influence of membrane lipid composition," Journal of Bioenergetics and Biomembranes, vol. 28, no. 1, pp. 69-76, 1996.

[16] G. K. Asimakis and L. A. Sordahl, "Effects of atractyloside and palmitoyl coenzyme A on calcium transport in cardiac mitochondria," Archives of Biochemistry and Biophysics, vol. 179, no. 1, pp. 200-210, 1977.

[17] E. Chávez, C. Zazueta, N. García, E. Martínez-Abundis, N. Pavón, and L. Hernández-Esquivel, "Titration of cardiolipin by either $10-\mathrm{N}$-nonyl acridine orange or acridine orange sensitizes the adenine nucleotide carrier to permeability transition," Journal of Bioenergetics and Biomembranes, vol. 40, no. 2, pp. 77-84, 2008.

[18] E. Chávez, M. Franco, H. Reyes-Vivas, C. Zazueta, J. Ramírez, and R. Carrillo, "Hypothyroidism renders liver mitochondria resistant to the opening of membrane permeability transition pore," Biochimica et Biophysica Acta, vol. 1407, no. 3, pp. 243-248, 1998.

[19] C. Zazueta, M. Franco, F. Correa et al., "Hypothyroidism provides resistance to kidney mitochondria against the injury induced by renal ischemia-reperfusion," Life Sciences, vol. 80, no. 14, pp. 1252-1258, 2007.

[20] C. Pantos, V. Malliopoulou, I. Mourouzis et al., "Propylthiouracil-induce hypothyroidism is associated with increased tolerance of the isolated rat heart to ischaemiareperfusion," Journal of Endocrinology, vol. 178, no. 3, pp. 427-435, 2003.

[21] M. Masztalerz, Z. Wlodarczyk, J. Czuczejko, M. Slupski, and J. Kedziora, "Superoxide anion as a marker of ischemia-reperfusion injury of the transplanted kidney," Transplantation Proceedings, vol. 38, no. 1, pp. 46-48, 2006.

[22] N. García, C. Zazueta, M. El-Hafidi et al., "Cyclosporin A inhibits UV-radiation-induced membrane damage but is unable to inhibit carboxyatractyloside-induced permeability transition," Radiation research, vol. 172, no. 5, pp. 575-583, 2009.

[23] E. Doran and A. P. Halestrap, "Cytochrome c release from isolated rat liver mitochondria can occur independently of outer-membrane rupture: possible role of contact sites," Biochemical Journal, vol. 348, no. 2, pp. 343-350, 2000.

[24] N. Pavón, A. Aranda, N. García, L. Hernández-Esquivel, and E. Chávez, "In hyperthyroid rats octylguanidine protects the heart from reperfusion damage," Endocrine, vol. 35, no. 6, pp. 158-165, 2009.

[25] E. Chávez, R. Moreno-Sánchez, C. Zazueta, H. Reyes-Vivas, and D. Arteaga, "Intramitochondrial $\mathrm{K}^{+}$as activator of carboxyatractyloside-induced $\mathrm{Ca}^{2+}$ release," Biochimica et Biophysica Acta, vol. 1070, no. 2, pp. 461-466, 1991.

[26] P. Venditti, R. De Rosa, and S. Di Meo, "Effect of thyroid state on susceptibility to oxidants and swelling of mitochondria from rat tissues," Free Radical Biology and Medicine, vol. 35, no. 5, pp. 485-494, 2003.

[27] E. Fernández-Vizarra, J. A. Enriquez, A. Pérez-Martos, J. Montoya, and P. Fernández-Silva, "Mitochondrial gene expression is regulated at multiple levels and differentially in the heart and liver by thyroid hormones," Current Genetics, vol. 54, no. 1, pp. 13-22, 2008.

[28] E. Yehuda-Shnaidman, B. Kalderon, N. Azazmeh, and J. BarTana, "Gating of the mitochondrial permeability transition pore by thyroid hormone," FASEB Journal, vol. 24, no. 1, pp. 93-104, 2010. 
[29] E. Yehuda-Shnaidman, B. Kalderon, and J. Bar-Tana, "Modulation of mitochondrial transition pore components by thyroid hormone," Endocrinology, vol. 146, no. 5, pp. 2462-2472, 2005.

[30] D. V. Cokkinos and C. Pantos, "Myocardial protection: a new holy grail of contemporary cardiology," Hellenic Journal of Cardiology, vol. 46, no. 4, pp. 249-257, 2005.

[31] N. García, F. Correa, and E. Chávez, "On the role of the respiratory complex I on membrane permeability transition," Journal of Bioenergetics and Biomembranes, vol. 37, no. 1, pp. 17-23, 2005.

[32] T. Munzel, T. Gori, R. M. Bruno, and S. Taddei, "Is oxidative stress a therapeutic target in cardiovascular disease?" European Heart Journal, vol. 31, no. 22, pp. 2741-2748, 2010.

[33] L. Zhang, J. R. Parrat, G. H. Beastall, N. J. Pyne, and B. L. Furman, "Streptozotocin diabetes protects against arrhthmias in isolated hearts: role of hypothyroidism," European Journal of Pharmacology, vol. 245, no. 2-3, pp. 269-276, 2002.

[34] I. Bobadilla, M. Franco, D. Cruz, J. Zamora, S. G. Robles, and E. Chávez, "Hypothyroidism provides resistance to reperfusion injury following myocardium ischemia," International Journal of Biochemistry and Cell Biology, vol. 33, no. 5, pp. 399-506, 2001.

[35] G. Capasso, N. G. De Santo, and R. Kinne, "Thyroid hormones and renal transport: cellular and biochemical aspects," Kidney International, vol. 32, no. 4, pp. 443-451, 1987.

[36] I. van Hoek and S. Daminet, "Interactions between thyroid and kidney function in pathological conditions of these organ systems: a review," General and Comparative Endocrinology, vol. 160, no. 3, pp. 205-215, 2009.

[37] F. Vargas, J. M. Moreno, I. Rodríguez-Gómez et al., "Vascular and renal function in experimental thyroid disorders," European Journal of Endocrinology, vol. 154, no. 2, pp. 197-212, 2006.

[38] M. Franco, N. A. Bobadilla, J. Suárez, E. Tapia, L. Sánchez, and J. Herrera-Acosta, "Participation of adenosine in the renal hemodynamic abnormalities of hypothyroidism," American Journal of Physiology, vol. 270, no. 2, pp. F254F262, 1996.

[39] D. M. Gillum, S. A. Falk, W. S. Hammond, and J. D. Conger, "Glomerular dynamics in the hypothyroid rat and the role of the renin-angiotensin system," American Journal of Physiology, vol. 253, no. 1, part 2, pp. F170-F179, 1987.

[40] M. G. Collis, "The vasodilator role of adenosine," Pharmacology and Therapeutics, vol. 41, no. 1-2, pp. 143-162, 1989.

[41] H. Osswald, "The role of adenosine in the regulation of glomerular filtration rate and renin secretion," Trends in Pharmacological Sciences, vol. 5, no. 1, 1984.

[42] W. S. Spielman and C. I. Thompson, "A proposed role for adenosine in the regulation of renal hemodynamics and renin release," American Journal of Physiology, vol. 242, no. 5, pp. F423-F435, 1982.

[43] D. Mazurkiewicz and D. Saggerson, "Changes in the activities of adenosine-metabolizing enzymes in six regions of the rat brain on chemical induction of hypothyroidism," Biochemical Journal, vol. 261, no. 2, pp. 667-672, 1989.

[44] Z. Jamal and D. Saggerson, "Enzymes involved in adenosine metabolism in rat white and brown adipocytes. Effects of streptozotocin-diabetes, hypothyroidism, age and sex differences," Biochemical Journal, vol. 245, no. 3, pp. 881-886, 1987.

[45] J. J. Ohisalo, S. Stoneham, and L. Keso, "Thyroid status and adenosine content of adipose tissue," Biochemical Journal, vol. 246, no. 2, pp. 555-557, 1987.
[46] M. Franco, O. Galicia, A. Quintana, and F. Martínez, "Experimental hypothyroidism modifies specific binding of $\mathrm{A} 1$ and $\mathrm{A} 2 \mathrm{~A}$ analogues to adenosine receptors in the rat kidney," British Journal of Pharmacology, vol. 142, no. 3, pp. 461-468, 2004.

[47] L. M. Harrison-Bernard and L. G. Navar, "Renal cortical and medullary microvascular blood flow autoregulation in rat," Kidney International, vol. 50, supplement 57, pp. S23-S29, 1996.

[48] E. W. Holmes and V. A. DiScala, "Studies on the exaggerated natriuretic response to a saline infusion in the hypothyroid rat," Journal of Clinical Investigation, vol. 49, no. 6, pp. 1224-1236, 1970.

[49] S. Dimitrios, D. S. Emmanouel, M. D. Lindheimer, and A. I. Katz, "Mechanism of impaired water excretion in the hypothyroid rat," Journal of Clinical Investigation, vol. 54, no. 4, pp. 926-934, 1974.

[50] F. Michael, J. Kelley, H. Alpert, and C. A. Vaamonde, "Role of the distal delivery of filtrate in impaired renal dilution on the hypothyroid kidney," American Journal of Physiology, vol. 230, no. 3, pp. 699-705, 1976.

[51] R. W. Schrier, "Body water homeostasis: clinical disorders of urinary dilution and concentration," Journal of the American Society of Nephrology, vol. 17, no. 7, pp. 1820-1832, 2006.

[52] M. Miyamoto, Y. Yagil, T. Larson, C. Robertson, and R. L. Ñ. Jamison, "Effects of intrarenal adenosine on renal function and medullary blood flow in the rat," American Journal of Physiology, vol. 255, no. 6, pp. F1230-F1234, 1988.

[53] E. P. Silldorff, M. S. Kreisberg, and T. L. Pallone, "Adenosine modulates vasomotor tone in outer medullary descending vasa recta of the rat," Journal of Clinical Investigation, vol. 98, no. 1, pp. 18-23, 1996.

[54] H. J. Reineck and R. Parma, "Effect of medullary tonicity on urinary sodium excretion in the rat," Journal of Clinical Investigation, vol. 69, no. 4, pp. 971-978, 1982.

[55] A. Vial and G. Burnstock, "A2-purinoceptor-mediated relaxation in the guinea-pig coronary vasculature: a role for nitric oxide," British Journal of Pharmacology, vol. 109, no. 2, pp. 424-429, 1993.

[56] P. L. Martin and A. A. Potts, "The endothelium of the rat renal artery plays an obligatory role in A2 adenosine receptor-mediated relaxation induced by $5^{\prime}-\mathrm{N}$ ethylcarboxiamidoadenosine and N6-cyclopentil adenosine," Journal of Pharmacology and Experimental Therapeutics, vol. 270, no. 3, pp. 893-899, 1994.

[57] J. M. Li, R. A. Fenton, B. S. Cutler, and J. G. Dobson Jr., "Adenosine enhances nitric oxide production by vascular endothelial cells," American Journal of Physiology, vol. 269, no. 2, pp. C519-C523, 1995.

[58] M.-H. Yen, C. C. Wu, and W.-F. Chiou, "Partially endothelium-dependent vasodilator effect of adenosine in rat aorta," Hypertension, vol. 11, no. 6, pp. 514-518, 1988.

[59] R. J. Barrett and D. A. Droppleman, "Interactions of adenosine A1 receptor-mediated renal vasoconstriction with endogenous nitric oxide and Ang II," American Journal of Physiology, vol. 265, no. 5, pp. F651-F659, 1993.

[60] M. Franco, E. Tapia, F. Martínez et al., "Adenosine regulates renal nitric oxide production in hypothyroid rats," Journal of the American Society of Nephrology, vol. 10, no. 8, pp. 1681-1688, 1999.

[61] A. Quesada, J. Sainz, R. Wangensteen, I. Rodríguez-Gomez, F. Vargas, and A. Osuna, "Nitric oxide synthase activity in hyperthyroid and hypothyroid rats," European Journal of Endocrinology, vol. 147, no. 1, pp. 117-122, 2002. 
[62] J. M. Moreno, R. Wangensteen, J. Sainz et al., "Role of endothelium-derived relaxing factors in the renal response to vasoactive agents in hypothyroid rats," American Journal of Physiology, vol. 285, no. 1, pp. E182-E188, 2003.

[63] F. Vargas, A. Fernández-Rivas, J. GarcíaEstañ, and C. García del Río, "Endothelium-dependent and endotheliumindependent vasodilation in hyperthyroid and hypothyroid rats," Pharmacology, vol. 51, no. 5, pp. 308-314, 1995.

[64] D. J. Prentice and S. M. O. Hourani, "Activation of multiple sites by adenosine analogues in the rat isolated aorta," British Journal of Pharmacology, vol. 118, no. 6, pp. 1509-1517, 1996.

[65] V. Ralevic and G. Burnstock, "Receptors for purines and pyrimidines," Pharmacological Reviews, vol. 50, no. 3, pp. 413-492, 1998.

[66] K. J. Miller and B. J. Hoffman, "Adenosine A3 receptors regulate serotonin transport via nitric oxide and c GMP," Journal of Biological Chemistry, vol. 269, no. 44, pp. 2735127356, 1994.

[67] G. Baños, F. Martínez, J. I. Grimaldo, and M. Franco, "Adenosine participates in regulation of smooth muscle relaxation in aortas from rats with experimental hypothyroidism," Canadian Journal of Physiology and Pharmacology, vol. 80, no. 6, pp. 507-514, 2002.

[68] J. M. Sabio, M. Rodríguez-Maresca, J. D. Luna, C. García del Rio, and F. Vargas, "Vascular reactivity to vasoconstrictors in aorta and renal vasculature of hyperthyroid and hypothyroid rats," Pharmacology, vol. 49, no. 4, pp. 257-264, 1994.

[69] R. D. Gunasekera and H. Kuriyama, "The influence of thyroid states upon responses of the rat aorta to catecholamines," British Journal of Pharmacology, vol. 99, no. 3, pp. 541-547, 1990.

[70] R. B. Meyer and W. Hope, "Evidence that A2 purinoceptors are involved in the endothelium-dependent relaxation of the rat thoraxic aorta," British Journal of Pharmacology, vol. 100, no. 3, pp. 576-580, 1990.

[71] J. P. Headrick and R. M. Berne, "Endothelium-dependent and independent relaxations to adenosine in guinea pig aorta," American Journal of Physiology, vol. 259, no. 1, pp. H62-H67, 1990.

[72] R. F. Furchgott, "Role of endothelium in responses of vascular smooth muscle," Circulation Research, vol. 53, no. 5, pp. 557-573, 1983.

[73] J. Li, R. A. Fenton, H. B. Wheeler et al., "Adenosine A2a receptors increase arterial endothelial cell nitric oxide," Journal of Surgical Research, vol. 80, no. 2, pp. 357-364, 1998.

[74] A. Vials and G. Burnstock, "A2 purinoceptor-mediated relaxation in the guinea pig coronary vasculature: role for nitric oxide," British Journal of Pharmacology, vol. 109, no. 2, pp. 424-429, 1993.

[75] P. Vuorinen, I. Porsti, T. Metsa-Ketela, V. Manninen, H. Vapaatalo, and K. E. Laustiola, "Endothelium-dependent and -independent effects of exogenous ATP, adenosine, GTP, and guanosine on vascular tone and cyclic nucleotide accumulation of rat mesenteric artery," British Journal of Pharmacology, vol. 105, no. 2, pp. 279-284, 1992.

[76] K. Yagi, I. Nishino, M. Eguchi, M. Kitagawa, Y. Miura, and T. Mizoguchi, "Involvement of ecto-ATPase as an ATP receptor in the stimulatory effect of extracellular ATP on NO release in bovine aorta endothelial cells," Biochemical and Biophysical Research Communications, vol. 203, no. 2, pp. 1237-1243, 1994.
[77] J. Linden, "Cloned adenosine A3 receptors: pharmacological properties, species differences and receptor functions," Trends in Pharmacological Sciences, vol. 15, no. 2, pp. 298-306, 1994.

[78] C. E. Muller, "A1-adenosine receptor antagonist," Expert Opinion on Therapeutic Patents, vol. 7, no. 5, pp. 419-440, 1997.

[79] H. Moritoki, T. Matsugi, H. Takase, H. Ueda, and A. Tanioka, "Evidence for the involvement of cyclic GMP in adenosineinduced, age-dependent vasodilatation," British Journal of Pharmacology, vol. 100, no. 3, pp. 569-575, 1990.

[80] A. E. Hak, H. A. Pols, T. J. Visser, H. A. Drexhage, A. Hofman, and J. C. Witteman, "Subclinical hypothyroidism is an independent risk factor for atherosclerosis and myocardial infarction in elderly women: the Rotterdam study," Annals of Internal Medicine, vol. 132, no. 4, pp. 270-278, 2000.

[81] M. Aviram, M. Rosenblat, C. L. Bisgaier, R. S. Newton, S. L. Primo-Parmo, and B. N. La Du, "Paraoxonase inhibits highdensity lipoprotein oxidation and preserves its functions. A possible peroxidative role for paraoxonase," Journal of Clinical Investigation, vol. 101, no. 8, pp. 1581-1590, 1998.

[82] S. Deakin, I. Leviev, M. Gomaraschi, L. Calabresi, G. Franceschini, and R. W. James, "Enzymatically active paraoxonase- 1 is located at the external membrane of producing cells and released by a high affinity, saturable, desorption mechanism," Journal of Biological Chemistry, vol. 277, no. 6, pp. 4301-4308, 2002.

[83] A. Kontush, S. Chantepie, and M. J. Chapman, "Small, dense HDL particles exert potent protection of atherogenic LDL against oxidative stress," Arteriosclerosis, Thrombosis, and Vascular Biology, vol. 23, no. 10, pp. 1881-1888, 2003.

[84] C. Mineo, H. Deguchi, J. H. Griffin, and P. W. Shaul, "Endothelial and antithrombotic actions of HDL," Circulation Research, vol. 98, no. 11, pp. 1352-1364, 2006.

[85] G. W. Cockerill, K. A. Rye, J. R. Gamble, M. A. Vadas, and P. J. Barter, "High-density lipoproteins inhibit cytokineinduced expression of endothelial cell adhesion molecules," Arteriosclerosis, Thrombosis, and Vascular Biology, vol. 15, no. 11, pp. 1987-1994, 1995.

[86] L. Calabresi, G. Franceschini, C. R. Sirtori et al., "Inhibition of VCAM-1 expression in endothelial cells by reconstituted high density lipoproteins," Biochemical and Biophysical Research Communications, vol. 238, no. 1, pp. 61-65, 1997.

[87] A. R. Cappola and P. W. Ladenson, "Hypothyroidism and atherosclerosis," Journal of Clinical Endocrinology and Metabolism, vol. 88, no. 6, pp. 2438-2444, 2003.

[88] M. P. Vanderpump, W. M. Tunbridge, J. M. French et al., "The development of ischemic heart disease in relation to autoimmune thyroid disease in a 20-year follow-up study of an English community," Thyroid, vol. 6, no. 3, pp. 155-160, 1996.

[89] S. Razvi, J. U. Weaver, M. P. Vanderpump, and S. H. Pearce, "The incidence of ischemic heart disease and mortality in people with subclinical hypothyroidism: reanalysis of the Whickham Survey cohort," Journal of Clinical Endocrinology and Metabolism, vol. 95, no. 4, pp. 1734-1740, 2010.

[90] N. Rodondi, A. B. Newman, E. Vittinghoff et al., "Subclinical hypothyroidism and the risk of heart failure, other cardiovascular events, and death," Archives of Internal Medicine, vol. 165, no. 21, pp. 2460-2466, 2005.

[91] J. J. Staub, B. U. Althaus, H. Engler et al., "Spectrum of subclinical and overt hypothyroidism: effect on thyrotropin, prolactin, and thyroid reserve, and metabolic impact on peripheral target tissues," American Journal of Medicine, vol. 92, no. 6, pp. 631-642, 1992. 
[92] B. Staels, A. Van Tol, L. Chan, H. Will, G. Verhoeven, and J. Auwerx, "Alterations in thyroid status modulate apolipoprotein, hepatic triglyceride lipase, and low density lipoprotein receptor in rats," Endocrinology, vol. 127, no. 3, pp. 1144-1152, 1990.

[93] A. Chait, E. L. Bierman, and J. J. Albers, "Regulatory role of triiodothyronine in the degradation of low density lipoprotein by cultured human skin fibroblasts," Journal of Clinical Endocrinology and Metabolism, vol. 48, no. 5, pp. 887-889, 1979.

[94] K. W. Walton, P. J. Scott, P. W. Dykes, and J. W. Davies, “The significance of alterations in serum lipids in thyroid dysfunction. II. Alterations of the metabolism and turnover of 131I-low-density lipoproteins in hypothyroidism and thyrotoxicosis," Clinical Science, vol. 29, no. 2, pp. 217-238, 1965.

[95] G. R. Thompson, A. K. Soutar, F. A. Spengel, A. Jadhav, S. J. Gavigan, and N. B. Myant, "Defects of receptormediated low density lipoprotein catabolism in homozygous familial hypercholesterolemia and hypothyrodism in vivo," Proceedings of the National Academy of Sciences of the United States of America, vol. 78, no. 4, pp. 2591-2595, 1981.

[96] O. Bakker, F. Hudig, S. Meijssen, and W. M. Wiersinga, "Effects of triiodothyronine and amiodarone on the promoter of the human LDL receptor gene," Biochemical and Biophysical Research Communications, vol. 249, no. 2, pp. 517-521, 1998.

[97] O. Pérez-Méndez, J. E. Carreón-Torres, M. Franco, and M. A. Juárez-Oropeza, "HDL physicochemical characteristics as determinants of their plasma concentrations: what we have learned from thiazolidinediones," in HDL and LDL Cholesterol: Physiology and Clinical Significance, F. Columbus, Ed., Nova Science, 2009.

[98] B. U. Althaus, J. J. Staub, A. Ryff-De Leche, A. Oberhansli, and H. B. Stahelin, "LDL/HDL-changes in subclinical hypothyroidism: possible risk factors for coronary heart disease," Clinical Endocrinology, vol. 28, no. 2, pp. 157-163, 1988.

[99] P. Caron, C. Calazel, H. J. Parra, M. Hoff, and J. P. Louvet, "Decreased HDL cholesterol in subclinical hypothyroidism: the effect of L-thyroxine therapy," Clinical Endocrinology, vol. 33, no. 4, pp. 519-523, 1990.

[100] S. Valdemarsson, P. Hedner, and P. Nilsson-Ehle, "Dyslipoproteinaemia in hypothyroidism of pituitary origin: effects of L-thyroxine substitution on lipoprotein lipase, hepatic lipase, and on plasma lipoproteins," Acta Endocrinologica, vol. 103, no. 2, pp. 192-197, 1983.

[101] E. Muls, M. Rosseneu, V. Blaton, E. Lesaffre, G. Lamberigts, and P. De Moor, "Serum lipids and apoliproteins A-I, A-II and B in primary hypothyroidism before and during treatment," European Journal of Clinical Investigation, vol. 14, no. 1, pp. 12-15, 1984.

[102] A. G. Scottolini, N. V. Bhagavan, T. H. Oshiro, and S. Y. Abe, "Serum high-density lipoprotein cholesterol concentrations in hypo- and hyperthyroidism," Clinical Chemistry, vol. 26, no. 5, pp. 584-587, 1980.

[103] M. J. Diekman, N. Anghelescu, E. Endert, O. Bakker, and W. M. Wiersinga, "Changes in plasma low-density lipoprotein (LDL) - and high-density lipoprotein cholesterol in hypoand hyperthyroid patients are related to changes in free thyroxine, not to polymorphisms in LDL receptor or cholesterol ester transfer protein genes," Journal of Clinical Endocrinology and Metabolism, vol. 85, no. 5, pp. 1857-1862, 2000.
[104] C. Meier, J. J. Staub, C. B. Roth et al., "TSH-controlled L-thyroxine therapy reduces cholesterol levels and clinical symptoms in subclinical hypothyroidism: a double blind, placebo-controlled trial (Basel Thyroid Study)," Journal of Clinical Endocrinology and Metabolism, vol. 86, no. 10, pp. 4860-4866, 2001.

[105] M. Franco, G. Castro, L. Romero et al., "Decreased activity of lecithin: cholesterol acyltransferase and hepatic lipase in chronic hypothyroid rats: implications for reverse cholesterol transport," Molecular and Cellular Biochemistry, vol. 246, no. 1-2, pp. 51-56, 2003.

[106] N. D. Ridgway and P. J. Dolphin, "Serum activity and hepatic secretion of lecithin: cholesterol acyltransferase in experimental hypothyroidism and hypercholesterolemia," Journal of Lipid Research, vol. 26, no. 11, pp. 1300-1313, 1985.

[107] G. Brenta, G. Berg, P. Arias et al., "Lipoprotein alterations, hepatic lipase activity, and insulin sensitivity in subclinical hypothyroidism: response to L-T(4) treatment," Thyroid, vol. 17, no. 5, pp. 453-460, 2007.

[108] C. Huesca-Gómez, M. Franco, G. Luc et al., "Chronic hypothyroidism induces abnormal structure of high-density lipoproteins and impaired kinetics of apolipoprotein A-I in the rat," Metabolism, vol. 51, no. 4, pp. 443-450, 2002.

[109] L. Johansson, M. Rudling, T. S. Scanlan et al., "Selective thyroid receptor modulation by GC-1 reduces serum lipids and stimulates steps of reverse cholesterol transport in euthyroid mice," Proceedings of the National Academy of Sciences of the United States of America, vol. 102, no. 29, pp. 10297-10302, 2005.

[110] N. R. Webb, L. Cai, K. S. Ziemba et al., "The fate of HDL particles in vivo after SR-BI-mediated selective lipid uptake," Journal of Lipid Research, vol. 43, no. 11, pp. 1890-1898, 2002.

[111] M. Lacasaña, I. López-Flores, M. Rodríguez-Barranco et al., "Interaction between organophosphate pesticide exposure and PON1 activity on thyroid function," Toxicology and Applied Pharmacology, vol. 249, no. 1, pp. 16-24, 2010.

[112] M. Aviram, E. Hardak, J. Vaya et al., "Human serum paraoxonases (PON1) Q and R selectively decrease lipid peroxides in human coronary and carotid atherosclerotic lesions: PON1 esterase and peroxidase-like activities," Circulation, vol. 101, no. 21, pp. 2510-2517, 2000.

[113] E. Carreón-Torres, K. Rendón-Sauer, M. Monter Garrido et al., "Rosiglitazone modifies HDL structure and increases HDL-apo AI synthesis and catabolism," Clinica Chimica Acta, vol. 401, no. 1-2, pp. 37-41, 2009.

[114] F. Azizi, F. Raiszadeh, M. Solati, A. Etemadi, M. Rahmani, and M. Arabi, "Serum paraoxonase 1 activity is decreased in thyroid dysfunction," Journal of Endocrinological Investigation, vol. 26, no. 8, pp. 703-709, 2003.

[115] G. Baskol, H. Atmaca, F. Tanriverdi, M. Baskol, D. Kocer, and F. Bayram, "Oxidative stress and enzymatic antioxidant status in patients with hypothyroidism before and after treatment," Experimental and Clinical Endocrinology \& Diabetes, vol. 115, no. 8, pp. 522-526, 2007.

[116] S. E. Nissen, E. M. Tuzcu, P. Schoenhagen et al., "Statin therapy, LDL cholesterol, C-reactive protein, and coronary artery disease," The New England Journal of Medicine, vol. 352, no. 1, pp. 29-38, 2005.

[117] I. Tancevski, P. Eller, J. R. Patsch, and A. Ritsch, "The resurgence of thyromimetics as lipid-modifying agents," Current Opinion in Investigational Drugs, vol. 10, no. 9, pp. 912-918, 2009. 
[118] F. Flamant, J. D. Baxter, D. Forrest et al., "International union of pharmacology. LIX. The pharmacology and classification of the nuclear receptor superfamily: thyroid hormone receptors," Pharmacological Reviews, vol. 58, no. 4, pp. 705-711, 2006.

[119] B. Gloss, S. Trost, W. Bluhm et al., "Cardiac ion channel expression and contractile function in mice with deletion of thyroid hormone receptor alpha or beta," Endocrinology, vol. 142, no. 2, pp. 544-550, 2001. 


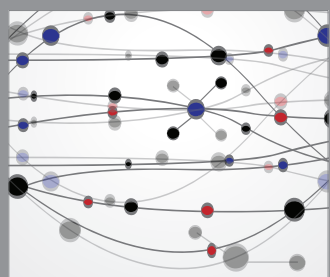

The Scientific World Journal
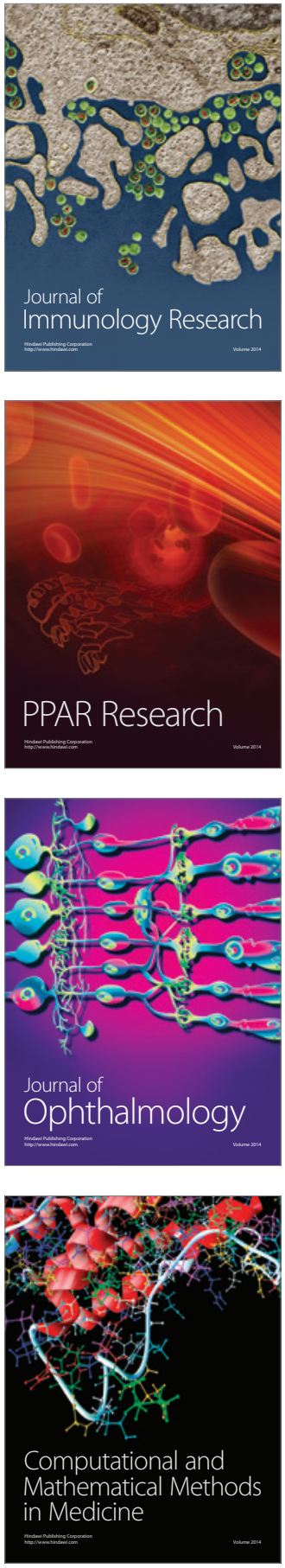

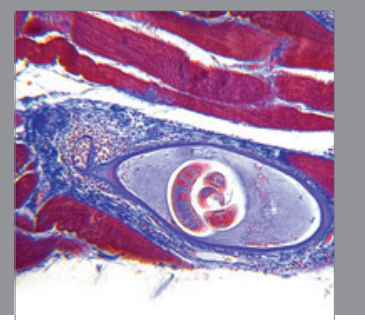

Gastroenterology

Research and Practice
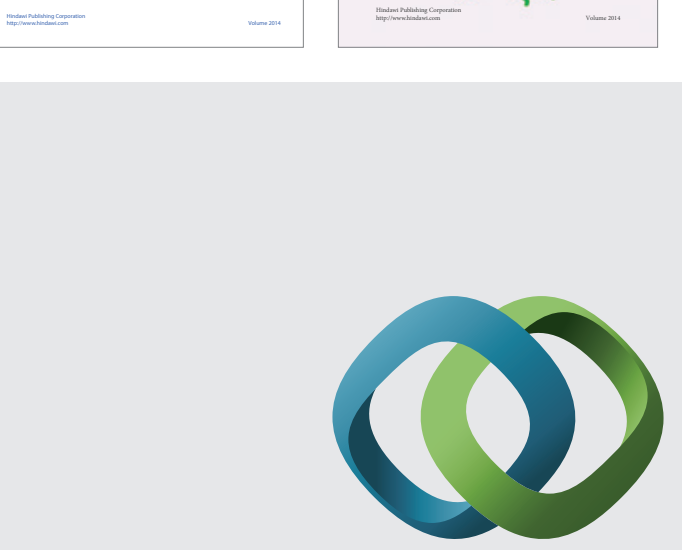

\section{Hindawi}

Submit your manuscripts at

http://www.hindawi.com
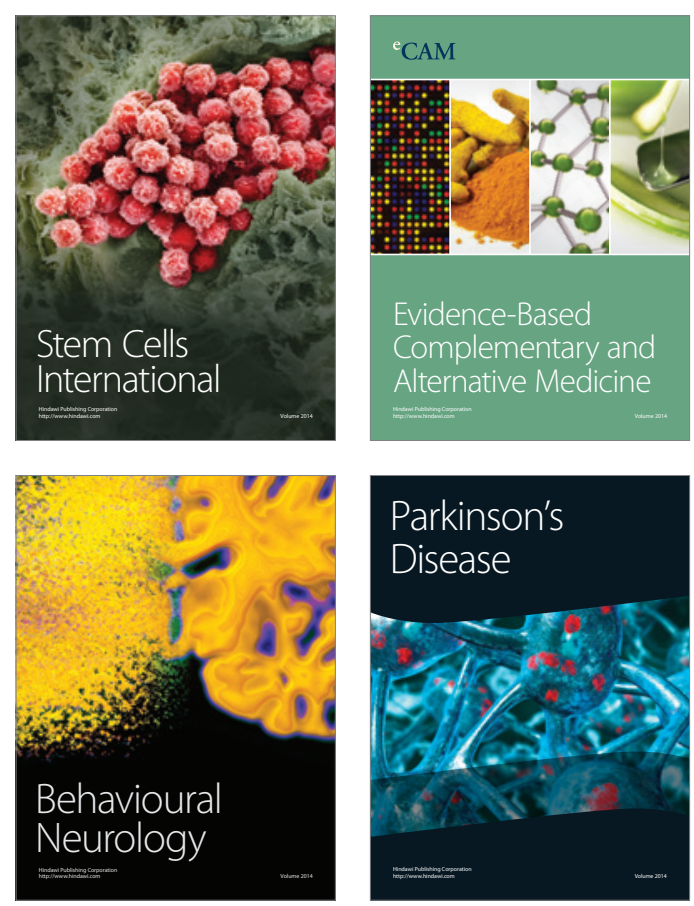

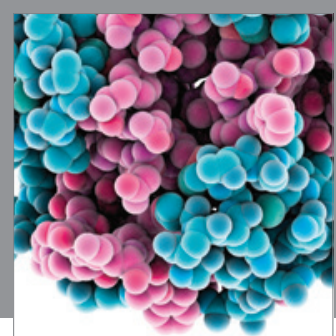

Journal of
Diabetes Research

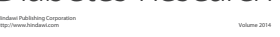

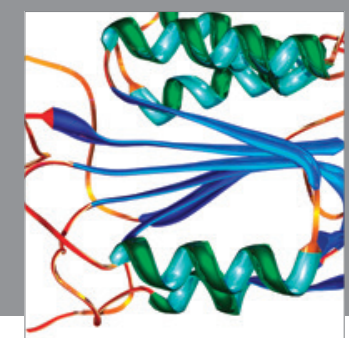

Disease Markers
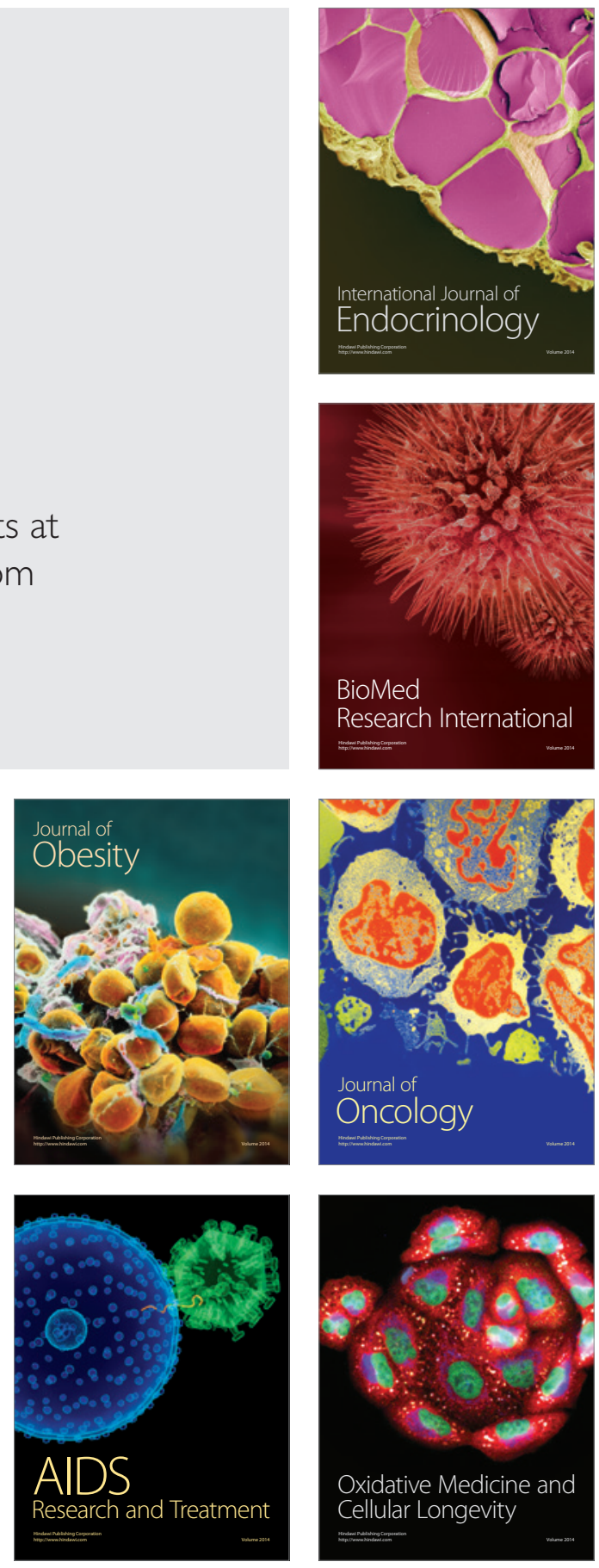